NBER WORKING PAPER SERIES

\title{
EARLY CHILDHOOD EDUCATION BY MOOC: LESSONS FROM SESAME STREET
}

\author{
Melissa S. Kearney \\ Phillip B. Levine \\ Working Paper 21229 \\ http://www.nber.org/papers/w21229 \\ NATIONAL BUREAU OF ECONOMIC RESEARCH \\ 1050 Massachusetts Avenue \\ Cambridge, MA 02138 \\ June 2015
}

The authors thank Riley Wilson for exceptional research assistance throughout this project. Amy Wickett also provided valuable assistance creating our coverage measure. This paper has benefitted tremendously from discussions with Liz Cascio, Doug Miller, Ben Olken, Diane Schanzenbach, and Sergio Urzua, as well as the comments of participants of seminars at MIT, Harvard University, University of Maryland, Wellesley College, Northwestern, the University of Illinois, the Federal Trade Commission, Georgetown University, and Williams College. We also thank Michael Henry at the University of Maryland Libraries (Special Collections in Mass Media \& Culture) for his assistance in collecting archived Sesame Street information. We gratefully acknowledge financial support from the Spencer Foundation. The views expressed herein are those of the authors and do not necessarily reflect the views of the National Bureau of Economic Research.

NBER working papers are circulated for discussion and comment purposes. They have not been peer-reviewed or been subject to the review by the NBER Board of Directors that accompanies official NBER publications.

(C) 2015 by Melissa S. Kearney and Phillip B. Levine. All rights reserved. Short sections of text, not to exceed two paragraphs, may be quoted without explicit permission provided that full credit, including $\odot$ notice, is given to the source. 
Early Childhood Education by MOOC: Lessons from Sesame Street

Melissa S. Kearney and Phillip B. Levine

NBER Working Paper No. 21229

June 2015, Revised September 2016

JEL No. I24,J24

\begin{abstract}
$\underline{\text { ABSTRACT }}$
This paper investigates whether preschool children exposed to Sesame Street when it began in 1969 experienced improved educational and labor market outcomes subsequently. We exploit geographic variation in broadcast reception derived from technological limitations, including distance to a broadcast tower and UHF versus VHF transmission. We relate this variation to Census data on grade-for-age status, educational attainment, and labor market outcomes in 1980, 1990, and 2000, respectively. The results indicate that Sesame Street improved school readiness, particularly for boys and children living in economically disadvantaged areas. The estimated impact on ultimate educational attainment and labor market outcomes is inconclusive.
\end{abstract}

\author{
Melissa S. Kearney \\ Department of Economics \\ University of Maryland \\ 3105 Tydings Hall \\ College Park, MD 20742 \\ and NBER \\ kearney@econ.umd.edu \\ Phillip B. Levine \\ Department of Economics \\ Wellesley College \\ 106 Central Street \\ Wellesley, MA 02481 \\ and NBER \\ plevine@wellesley.edu
}




\section{Early Childhood Education by MOOC: Lessons from Sesame Street Melissa S. Kearney and Phillip B. Levine}

\section{INTRODUCTION}

In recent years, early childhood education, designed to improve subsequent life outcomes for students who participate, has received considerable attention. Programs like Perry Preschool, Head Start, universal pre-kindergarten, and others have taken center stage. Academic research has generally supported the role that early childhood education can play in improving outcomes for disadvantaged children, as reviewed by Duncan and Magnuson (2013), and that has led to specific proposals from those in the policy community (cf. Cascio and Schanzenbach, 2014). Both sides of the political spectrum have promoted its benefits (cf. Council of Economic Advisers, 2015; and Stevens, 2015).

For all of this attention, it is surprising that perhaps the biggest, yet least costly, early childhood intervention, Sesame Street, has largely been left out of this policy and research conversation. This show initially aired in 1969; its fundamental goal was to reduce the educational deficits experienced by disadvantaged youth based on differences in their preschool environment. It was a smash hit immediately upon its introduction, receiving tremendous critical acclaim and huge ratings. It cost pennies on the dollar relative to other early childhood interventions. Well-designed research studies conducted at that time, reviewed in detail below, indicate that the show had a substantial and immediate impact on test scores, comparable in size to those observed in early Head Start evaluations. Yet, we know little else regarding its effectiveness, particularly over the long-term. ${ }^{1}$

\footnotetext{
${ }^{1}$ Fisch and Truglio (2001) review the research exploring the impact of Sesame Street. In terms of short-term effects, Bogatz and Ball (1971) provide a major contribution to this literature, finding substantial improvements in academic achievement within the context of an experimental setting. Diaz-Guerrero, et al. (1976) find similar results regarding the introduction of Sesame Street in Mexico. Paulson (1974) also uses random assignment, finding that the show
} 
An analysis of the effectiveness of Sesame Street can potentially also inform current discussions regarding the ability of Massive Open Online Courses (MOOCs) to deliver educational improvements, in particular for younger children. In essence, Sesame Street was the first MOOC. Although MOOCs differ in what they entail, Sesame Street satisfies the basic feature of electronic transmission of online educational material. Both Sesame Street and MOOCs provide educational interventions at a fraction of the cost of more traditional classroom settings. Most (but not all) MOOCs today exist at the level of higher education, which clearly differs from a preschool intervention. Our knowledge of the ability of MOOCs to improve outcomes for its participants is so limited, though, that any proper evaluation of the impact of electronic transmission of educational content is beneficial. ${ }^{2}$

Additional evidence on the impact of Sesame Street can also inform a discussion regarding the potential ability of television to have a positive impact on society. Typically, commentary on the role of television in society focuses on the potential for negative effects. ${ }^{3}$ Recent evidence, however, has indicated some beneficial social effects of the introduction of television (Gentzkow and Shapiro, 2008; Jensen and Oster, 2009). ${ }^{4}$ In other research, we have shown that the depiction of teen motherhood on the MTV reality TV series, 16 and Pregnant, led

improved social outcomes like cooperation. Some research has examined longer-term effects, but that work focuses on differences in outcomes between those who watch versus those who do not, without accounting for the selection into groups (cf. Huston, et al., 2001). This leaves the question of a causal impact open.

${ }^{2}$ Marcus (2013) raises this issue regarding the lack of evidence examining the effectiveness of MOOCs (Hart, et al, 2015, is a recent exception). Sinha (2011), president of Khan Academy, writes that their own evaluation supports an effect despite their inability to provide experimental evidence. Luzer (2014) reports that an experimental investigation of Khan Academy, funded by the Department of Education, is to be conducted in 2015-16. Whether Khan Academy is a MOOC also remains an open question (Akanegbu, 2013). For our purposes, we are concerned with the general idea of student responses to low cost, electronic educational content and less focused on the specific definition of a MOOC.

${ }^{3}$ When Sesame Street was first introduced, Brown (1969) wrote: "Not until the closing weeks of 1969 did television offer a program series that really answered the long-standing criticism of the medium - namely that it takes a viewer's time without giving anything in return - and held out hope for a more substantive future."

${ }^{4}$ In contrast, Olken (2009) presents evidence indicating that access to television in Indonesia was harmful to social capital. 
to a sizable reduction in teen childbearing (Kearney and Levine, 2014). Sesame Street is another possible example of television that may provide social benefits in the form of improved educational performance, particularly for disadvantaged children. Whether it accomplished this is a matter of evaluating the evidence.

The purpose of this paper is to inform these issues by conducting a large-scale examination of the impact of the introduction of Sesame Street on early educational performance measures and to additionally consider longer-term educational and labor market outcomes. Our methodological approach exploits limitations in television technology, which restricted access to Sesame Street to about two-thirds of the population when it first aired in 1969 (Davis, 2008). As we describe in more detail below, Sesame Street mainly aired on stations affiliated with the Public Broadcasting System (PBS), which often broadcast on UHF (ultra-high frequency) channels. UHF reception was inferior to reception on VHF (very high frequency) channels for physical reasons and because many television sets at that time did not have the capability to receive a UHF signal (McDowell, 2006). Transmission distance also restricted access for some households. Our analysis takes advantage of the county-level variation in viewer's ability to watch Sesame Street generated by these technological constraints that existed when the show was introduced in 1969.

We combine this geographic variation in broadcast exposure with differences across birth cohorts in terms of children's ages at the time of the show's introduction. Children who were already beyond first-grade at the time of the show's introduction would not have been exposed during early childhood and hence would generally not have been affected by its introduction. Essentially, we investigate whether the educational outcomes among birth cohorts who were age 6 and under in 1969 and who lived in locations where broadcast reception for the show was high 
improved relative to older cohorts and those who lived in locations with limited broadcast reception. Improved relative outcomes for the prior group would strongly suggest a causal impact of exposure to the show. We implement this approach mainly using data from the 1980 , 1990, and 2000 Censuses. ${ }^{5}$ We augment our main analysis with an exploration of additional data from the 1980 High School and Beyond survey.

The results of our analysis provide evidence that Sesame Street's introduction generated a positive impact on educational outcomes through the early school years. More specifically, exposed cohorts of students with better reception capabilities were 14 percent more likely to be attending the grade that is appropriate for their age. This effect was particularly pronounced for boys, black, non-Hispanic children, and those living in economically disadvantaged areas. When we extend the lens farther, however, we are unable to detect statistically significant effects on ultimate educational attainment or labor market outcomes. The small estimated impact on wages in adulthood, though, is consistent with forecasts based on the estimated improvements in test scores and grade-for-age status brought about by the show's introduction.

\section{BACKGROUND}

\section{A. History of Sesame Street}

The early 1960s marked a change in thinking among child psychologists and educators, who began to reject the notion that cognitive ability was completely heritable (cf. Hunt, 1961). This sparked interest in early childhood interventions like Perry Preschool and Head Start, which were meant to improve academic preparation among young children. Sesame Street followed this legacy. It was first proposed in 1967 (Cooney, 1967) and first aired on November $10^{\text {th }}$, 1969. Its stated purpose was "to foster intellectual and cultural development in preschoolers" (p. 20).

${ }^{5}$ Cascio (2009) uses a similar technique tracking cohorts across successive cohorts in her analysis of the introduction of kindergarten in school districts in the 1960s and 1970s. 
Following its introduction, Sesame Street was mainly broadcast on PBS channels; of the 192 stations airing the show, 176 of them were affiliated with PBS. The majority of these stations (101) were broadcast on UHF channels rather than VHF channels, which introduced technological constraints that limited exposure to the show. As we detail below, only around two-thirds of the population lived in locations where Sesame Street could be received on their televisions.

Despite this technological constraint, Sesame Street immediately became a huge success. By January of 1970, over five million households tuned in to a typical episode (Clausen, 1970). Among those between ages 2 and 5, Cook, et al. (1975) estimate that between 28 and 36 percent watched Sesame Street in 1970; between 33 and 42 percent did so in 1971. To put its popularity in perspective, roughly one-third of the entire United States population watches the Super Bowl today. These numbers are even more remarkable within the context of the technological limitations that prevented around one-third of the population from watching it.

Sesame Street was really the first children's television programming explicitly focused on educational content. Popular shows among children at that time included Captain Kangaroo (CBS), Mister Rogers Neighborhood (PBS), Romper Room (locally produced), cartoons (e.g., The Jetsons, The Flintstones), and sitcoms (The Andy Griffith Show). Earlier shows prior to Sesame Street that explicitly targeted children include Looney Tunes, Tom and Jerry, Howdy Doody, and Kukla, Fran, and Ollie, among others. Some shows, like Mister Rogers Neighborhood, did focus on teaching social skills, such as getting along with others, but none focused on academic content in the way that Sesame Street did.

It is also important to recognize that at the time Sesame Street was introduced, preschool attendance was the exception, rather than the norm. According to our calculations using the 1970 
Census, only 9 percent and 19 percent of children ages 3 and 4, respectively, attended preschool. ${ }^{6}$ Among children age 5, 57 percent attended school (presumably kindergarten), but, at the time, kindergarten generally only lasted half a day. Many of those children would still have had the chance to watch Sesame Street (if they lived in a home that could receive the necessary broadcast signal) after school, since stations typically broadcast the show both in the morning and later in the afternoon. ${ }^{7}$

\section{B. Television Technology/History of $U H F$}

Early access to Sesame Street was limited by broadcast technology at the time of the show's introduction. The most important reason for limited access was that in some places, Sesame Street was broadcast on a UHF signal, as noted above. ${ }^{8}$ For the television viewer, the most straightforward distinction is that VHF channels are those between 2 and 13 and UHF channels are those greater than 13. A UHF broadcast meant lower rates of reception for two reasons. First, signals broadcast over VHF travel farther and their reception is less affected by mountains, buildings, and other obstacles. A household with a television capable of receiving both signals is more likely to be able to receive a VHF signal than a UHF signal.

In addition, in the time period under consideration, many television sets were not equipped to receive a UHF signal. Before 1952, there were no UHF channels broadcasting, initially because there were enough VHF channels to meet demand and, subsequently, because of World War II (the military wanted the rights to those frequencies) and a resulting Federal

\footnotetext{
${ }^{6}$ These estimates are comparable to those provided by Gibbs, Ludwig, and Miller (2013). Cascio (2009) describes the institutional background regarding the introduction of kindergarten across school districts in the United States, detailing its limited availability during this period.

${ }^{7}$ Based on 1980 Census data that we describe below, we calculate that 29 percent of children lived in locations where Sesame Street was broadcast only in the morning, 11 percent only in the afternoon, and 59 percent both in the morning and in the afternoon. We experimented with taking advantage of this variation in the data, but found insufficient power to identify differential effects.

${ }^{8}$ Webbink (1969) and Rothenberger (2004) provide useful discussions of the history of UHF broadcast technology and related public policy.
} 
Communications Commission (FCC) moratorium on granting new station licenses. ${ }^{9}$ When the moratorium was lifted in 1952, strong demand for additional stations led the FCC to expand channel options to include those broadcasting in UHF. Even then, television manufacturers typically did not build sets that included UHF tuners. With no tuners, original programming was limited; with no original programming, there was no demand for the tuners.

This changed when the "All Channel Receiver Act" became law in 1962. This act, which took effect in 1964, required manufacturers to produce television sets that could receive both UHF and VHF signals. Televisions were expensive, though, costing roughly $\$ 700$ for a state-ofthe-art 25-inch color set in 1966 (TV Guide, 1966), compared to the median family income of $\$ 7,436$ in that same year (U.S. Bureau of the Census, 1968). This resulted in a slow diffusion of UHF signal receipt. In 1969, 95 percent of households owned television sets, but only 54 percent of those households had one that could receive a UHF signal (U.S. Bureau of the Census, 1970). We describe below how we use these constraints to identify the effect of potential exposure to Sesame Street programming on children's subsequent outcomes.

\section{ETS Study of Sesame Street's Impact}

Educational Testing Service (ETS) was hired right from the initial development of Sesame Street to design and implement an analysis that would examine whether children who watched the show performed better on a range of educational activities (Bogatz and Ball, 1971). Ex-ante, the design used in the first year following the show's introduction was a good one. Disadvantaged children in a number of locations were identified and randomly assigned to treatment and control groups, where treatment included explicit encouragement to watch the

\footnotetext{
${ }^{9}$ After World War II, in response to strong demand for new channels and the need to insure that signals from neighboring communities would not interfere, the moratorium was imposed to develop a viable licensing system. This moratorium is an important element in Gentzkow and Shapiro's (2008) analysis of preschool age exposure to television on children's standardized test scores.
} 
show. ${ }^{10}$ Clearly, the evaluators had no idea Sesame Street viewership would be so high. The experimental design failed because so many members of both the treatment and control groups watched it.

ETS adopted a different approach in the second year evaluation. This evaluation is based on experiences in Winston-Salem, NC and Los Angeles, CA and relies on viewing constraints among low-income households. In Winston-Salem, NC, cable television (in its infancy at this time) was just being introduced, enabling subscribers to watch Sesame Street in a location where reception would have been limited otherwise. But low-income households were unlikely to be able to afford cable service. ETS randomly assigned families with pre-school age children to control and treatment groups, where treatment group families were provided with cable television and the children in those households were encouraged to watch the show. In Los Angeles, Sesame Street was available on a UHF channel only and many low-income households did not have a television that could receive a UHF signal. In that location, ETS provided treatment group households with UHF converters for their television, enabling them to watch the show; again, children in treatment group households were encouraged to watch it.

The results of this ETS analysis provided support for a strong effect of Sesame Street. Positive effects were observed on a number of specific outcomes. Among their many results, they find a sizable impact of the show on the Peabody Picture Vocabulary (PPVT) test, which is standardized and frequently used as a general test of cognitive performance. Their PPVT findings imply that the treatment group experienced a 0.36 standard deviation relative increase in

\footnotetext{
${ }^{10}$ The component of encouragement is one that Cook, et al. (1975) criticize, arguing that doing so can highlight the importance of academic skills, which can have an impact on its own even in the absence of Sesame Street content.
} 
PPVT scores. ${ }^{11}$ This effect can be interpreted as the equivalent of around an additional full year of learning. ${ }^{12}$

Our study complements this experimental evidence by broadening the scope to the population level and considering how an entire generation of children were impacted. Although the value of randomized controlled trials is unquestioned, it is based on the behavior of a few hundred children in two specific locations. Our study applies the approach of a well-identified quasi-experiment based on hundreds of thousands of exposed cohorts of children nationwide. In addition, we consider the question of long-term outcomes. Cook, et al. (1975) note in their critique of the ETS study, "we could find no data of any reasonable quality to assess the crucial question of the long-term effects of viewing 'Sesame Street' on both learning and social development." This has remained a gap in the literature, which we attempt to fill in with this paper.

\section{Sesame Street and Head Start}

Along many dimensions, Sesame Street is a comparable intervention to Head Start. Both shared a common heritage, incorporating new ideas during the 1960s about the role that early childhood interventions can play in improving educational outcomes for disadvantaged children. Both had demonstrated evidence of short-term effectiveness. Gibbs, et al. (2013), Duncan and Magnuson (2013), and Shager, et al. (2014) report that the literature assessing the impact of Head Start on early childhood cognitive test scores yield similar effect sizes to those reported in Bogatz and Ball (1971) regarding Sesame Street. In fact, policy makers and analysts who were

\footnotetext{
${ }^{11}$ Bogatz and Ball (1971) report that the "encouraged" group experienced gains in PPVT scaled scores of 1.7 points between the beginning and end of the year. Members of the "not encouraged" group saw their scores fall by -3.7 points (see p. 105). Cook, et al. (1975) reports that the PPVT is designed to have a mean of 100 and a standard deviation of 15. The difference between the two groups of 5.4 points reflects 0.36 of a standard deviation increase.

${ }^{12}$ This translation is based on Hill, et al. (2008), which indicates that an effect size of 0.20 on nationally normed standardized tests is roughly equivalent to six additional months of learning.
} 
focused on early childhood education at the time specifically compared the two programs, noting that Sesame Street appeared to generate improvements in cognitive skills comparable to those of Head Start for a fraction of the cost. ${ }^{13}$

It is important to keep in mind, though, that the two interventions are actually substantively different from each other, not only in the nature of the intervention, but in their stated goals. Head Start was designed to be a comprehensive program with a variety of services beyond typical preschool education, including, for example, medical and dental services and family outreach. It certainly included a component designed to increase children's cognitive development as Sesame Street did, but it went far beyond that to address social and emotional development, improve self-confidence, address health deficiencies, and improve family functioning (Cooke, 1965). The initial goals of the Sesame Street program were more narrowly focused, extending beyond academic achievement only to address cultural development (music and the arts) and the awareness of basic emotions, including aggression and fear (Cooney, 1967). ${ }^{14}$ Because of these fundamental design differences it is not clear that we would expect similar long-term effects from the two programs.

\section{MethodS AND DATA}

\section{A. Overview}

\footnotetext{
${ }^{13}$ Zigler and Muenchow (1994) state that Nixon administration officials argued "we can get Sesame Street to reach poor kids by spending sixty-five cents per child ... Why should we spend over a thousand dollars per child on Head Start?" (p. 165). Cook, et al. (1975) similarly state: "why pay teachers more money, run programs such as Head Start, build new schools, and experiment with complex teaching machines when there already is a relatively inexpensive, easily expandable approach? ... Clearly, unless the 'Sesame Street' approach really is efficacious, there is the concern that the swell of enthusiasm for it could drown out other educational efforts to improve human resources." (p. $\mathrm{x}$ in the foreword).

${ }^{14}$ Edward Zigler, Director of the Office of Child Development (which oversaw Head Start) in the Nixon Administration responded to the White House's comparison of Sesame Street and Head Start by stating: "how long would a poor child have to watch Sesame Street to get his or her teeth filled? When nobody could answer, that was the end of the meeting." (Zigler and Muenchow, 1994). The point was that Head Start did much more than just try to impact educational skills.
} 
As described earlier, only two-thirds of households reportedly were able to receive the signal broadcasting Sesame Street when the show began in 1969. The general framework of our empirical approach is to determine the variation in "coverage" (likelihood of being able to receive the signal) across locations (counties). We then examine whether outcomes improve as coverage improves for those children who were of preschool age in 1969 relative to those who had already started school at that time. The latter group should have received little or no effect from the show. These coverage rates are largely determined by the distance to the closest television tower broadcasting Sesame Street and whether that tower transmits using UHF or VHF. Since the location of the television towers and the channel assigned to a station are functions of FCC decisions made years before Sesame Street aired, they should be unrelated to any subsequent changes in outcomes that occurred right after Sesame Street was introduced, but for the impact of the show. The remainder of this section provides the details regarding our implementation of this approach.

\section{B. Calculating Sesame Street Coverage Rates}

A critical data component of our empirical strategy is a measure of Sesame Street broadcast coverage rates across geographical areas. We need to know: (a) which television stations broadcast Sesame Street in a given area and (b) what share of households in a given area could receive that station's broadcast signal. Data from Children's Television Workshop (undated) indicate which stations aired Sesame Street in 1969/1970. Estimating what share of households in a given area could receive the signal from that station requires that we impute coverage based on supplementary data sources. 
For this purpose we rely heavily on data reported in the 1968-1969 edition of a trade publication, TV Factbook (Television Digest, Inc., 1968-1969). ${ }^{15}$ This data source provides a listing of every television station - including both commercial and non-commercial broadcasting in the United States, along with its technical specifications: channel number (which captures UHF/VHF), latitude and longitude of its broadcast tower, height of the tower, and transmission signal power. For all commercial stations, the publication also lists surrounding counties and coverage rates, as defined by the fraction of television households who have the ability to receive the signal from each station. ${ }^{16}$

Using this sample, we regress county-level coverage rates on the technical specifications of each channel - including UHF/VHF status, distance between the broadcast tower and the population centroid of each county, transmission power, and height of the tower - to establish the empirical relationships between those technical specifications and the coverage rate among commercial stations. We then apply those estimated relationships to the specifications of the non-commercial stations to obtain a simulated coverage rate at the county level for those stations. We assign to each county the station that provides the highest simulated coverage rate and use that rate as our measure of the percentage of households in that county that can watch Sesame Street in their homes. In the end, our process generates a national coverage rate of 65 percent, which aligns closely to national estimates of Sesame Street coverage made at that time. ${ }^{17}$

\footnotetext{
${ }^{15}$ Data Appendix I gives more details about our data procedure to estimate coverage rates.

${ }^{16}$ Reported coverage rates are categorical (greater than 50 percent, 25 to 50 percent, and 5 to 24 percent). We linearize these rates, assuming the categories reflect 90 percent, 40 percent, and 20 percent coverage, respectively. We have also experimented with alternative assumptions and non-parametric specifications, but the results based on these alternatives were consistent with our linearized approach. We focus on this approach because of the greater simplicity in estimation and interpretation.

${ }^{17}$ Clausen (1970) reports that the coverage rate was 69.4 percent the week of January 19-25 of 1970. The coverage rate data that we use refers to 1968-69, which is likely slightly lower than this level because some households upgraded their television sets over this interval, acquiring the ability to view UHF signals.
} 
Note that actual coverage rates for stations (commercial or non-commercial) are a function of technological factors as well as the share of households with a television that has a UHF tuner. One concern with using the actual measure of coverage would be that wealthier households are more likely to have UHF tuners in 1968. But, our measure of coverage is simulated based on the relationship between broadcast technology factors and observed coverage rates for commercial stations. Since we are not using actual coverage, but rather simulated coverage (which is based on the average relationship between signal receipt and technological factors like UHF transmission and distance to the tower), the variation across counties in our simulated measure of coverage is only a function of technological factors, not county-level UHFtelevision ownership rates. This is an advantage of using this simulated measure.

The regression results from estimating coverage (using the observed actual coverage rates from commercial stations) as a function of technological characteristics make clear the importance of UHF versus VHF in determining coverage. Coverage rates for a UHF station in the same county as the television tower are 42 percentage points lower than they are for a comparable VHF station in that county. This roughly corresponds to the limited number of televisions that could receive UHF signals at that time. Coverage in the county falls around another 20 percentage points for a UHF station if it is 100 miles away from the tower.

Figures 1 and 2 display all the stations that broadcast Sesame Street, distinguishing them by VHF/UHF status, and simulated county-level coverage rates. Figure 1 indicates that Southern California, Ohio, and the District of Columbia represent examples of heavily populated areas where Sesame Street was only accessible via a UHF signal. Figure 2 shows that these areas have very low rates of simulated coverage as well, reflecting the fact that UHF transmission substantially reduced access to the show. 
We also compare our simulated coverage rates to additional data on Sesame Street Nielsen ratings to provide further evidence that our measure of coverage adequately captures constraints on audience size. Local ratings data for children between the ages of 2 and 5 when Sesame Street was introduced are available for 28 metropolitan areas (Haydon, 1973). ${ }^{18}$ We link these areas to our constructed county level coverage data. Figure 3 presents a scatter plot of this relationship. It shows that coverage and ratings are positively related; the correlation coefficient between them is 0.48 . The slope also provides informative data. For every percentage point increase in coverage, ratings among 2 to 5 year olds increase by 0.58 percent. If preschool age children are proportionally distributed across counties, this result would suggest that over half of the children who have the technological capability to watch Sesame Street watch the show.

\section{Empirical Specifications}

Our main identification strategy relies on variation across cohorts and geography (counties) in children's potential exposure to Sesame Street programming. We focus on cohorts born between 1959 and 1968, who ranged in age from 1 to 10 years of age when Sesame Street was introduced in 1969. Another way to think about this cohort variation in exposure to the show is that individuals born between 1959 and 1963 would have been age 6 or older, and already in elementary school, at the time the show first aired. Individuals born between 1964 and 1968 would have been age 5 and below, and would have been exposed to the program during their preschool age years. The other dimension of variation in access to the show comes from the county-level Sesame Street coverage rate, defined (as described in detail above) to be the share

\footnotetext{
${ }^{18}$ The data in Haydon (1973) report the number of viewers between the ages of 2 and 5 who watch Sesame Street in each reported metropolitan area. We combine these data with population counts from the 1970 Census for this age group to generate the percentage of viewers.
} 
of television households in the county who were able to receive a signal over which Sesame Street was broadcast.

Our empirical strategy is to observe whether outcomes differ for cohorts of individuals who would have had preschool-age exposure to the show as compared to older cohorts and individuals who lived in counties with limited broadcast coverage. Any difference along these dimensions could reasonably be considered to be evidence of an impact of the show on educational outcomes.

Within this framework, the specific models we estimate take the following forms:

$$
\begin{gathered}
\text { Outcome }_{i j c}=\beta_{0}+\beta_{1} *\left(\text { preschool69 }_{i c} * \operatorname{SSCov}_{j}\right)+\beta_{2} \text { Policy }_{j c}+\beta_{3} X_{i j c}+\gamma_{c} * \gamma_{s}+\delta_{j}+\varepsilon_{i j c}(1) \\
\text { Outcome }_{i j c}=\beta_{0}+\sum_{c=1967 / 68}^{1973 / 74} \beta_{c} *\left(\gamma_{c} * S S \operatorname{Sov}_{j}\right)+\beta_{2} \text { Policy }_{j c}+\beta_{3} X_{i j c}+\gamma_{c} * \gamma_{s}+\delta_{j}+\varepsilon_{i j c}(2)
\end{gathered}
$$

where the dependent variable, Outcome $_{\mathrm{ijc}}$, represents different educational and labor market outcomes for individual $i$, in county $j$, in cohort $c$. The subscript $s$ indexes states. Sesame Street coverage rates, $S S C o v$, are only indexed by county; that variable is time-invariant and captures the technological constraints to watching the show that existed just before it was introduced. All reported standard errors are clustered at the county level.

In Equation (1), we estimate a difference-in-difference specification where $\beta_{1}$ captures the causal effect of interest. Birth cohorts are distinguished by those who would be preschool age when the show began in the fall of 1969 (preschool69 $i c)$. We include county fixed effects $\left(\delta_{j}\right)$ to capture time-invariant differences in outcomes across counties. We also include state*birth cohort fixed effects $\left(\gamma_{\mathrm{c}}{ }^{*} \gamma_{\mathrm{s}}\right)$ to capture time varying changes in outcomes across states, including state-level policy variation like the introduction of Medicaid and welfare generosity. The model 
also controls for a series of individual covariates, captured by $X_{i j c}$ : race/ethnicity, age, and, when it is available, socioeconomic status.

A potential source of omitted variable bias would occur if other policies or environmental conditions that would affect the educational outcomes of young children changed at the county level around the same time as Sesame Street was introduced. Two potential candidate policy changes that could lead to an omitted variable bias include the introduction of the Food Stamp program and increased expenditures on the Head Start program. The Food Stamp Program was introduced across counties in the U.S. between 1961 and 1975. Our model includes an indicator for having the Food Stamp Program in operation in the county in a given year, as measured by Hoynes, Schanzenbach, and Almond (2012). Our model also controls for Head Start expenditures in 1968 and 1972, as recorded by Ludwig and Miller (2007). ${ }^{19}$ These are the policy variables to which we refer in equations 1 and 2.

In Equation (2), we relax the pre-assignment of treatment and control groups by cohort, allowing for the effect of Sesame Street coverage to differ by grouped birth cohorts. We aggregate individuals from neighboring birth years to increase the power of this analysis. This provides a specification check to see if the "treatment effect" really starts with the appropriate groups of birth cohorts. In both cases, we also estimate models separately by race/ethnicity and gender. $^{20}$

\footnotetext{
${ }^{19}$ We are grateful to Diane Schanzenbach for providing us with this Food Stamp program indicator. We are also grateful to Jens Ludwig for providing the Head Start data. Those data provide Head Start expenditures by county in 1968 and 1972; we linearly interpolate to fill in values between the two years. Since Head Start largely enrolls fouryear-olds and school entry is at age 6, we treat these data as affecting 6 year olds in 1970 through 1974 . We linearly interpolate to fill in values between the two years.

${ }^{20} \mathrm{We}$ are unable to disaggregate individuals by socioeconomic status because of data limitations. The only feasible measure of SES is maternal education, but that only exists in our 1980 Census subsample for those individuals still living with their mothers. We include maternal education along with a missing value indicator for those who no longer live with their mother as explanatory variables, but the sample selection issues introduced by splitting the sample in this way are more difficult to overcome.
} 
Our primary measure of interest is access to Sesame Street broadcasting, not actual viewership of the show. In this sense, our approach identifies an "intent to treat" relationship, not a "treatment on the treated." If we had better ratings data, we could pursue an approach that would help us address the impact on the marginal viewer. As noted earlier, though, ratings data are only available for a limited subset of counties that are encompassed by 28 metropolitan areas. ${ }^{21}$ As a result, the question that we are best able to address with our analysis is what is the impact of making a show like Sesame Street more readily available to children, not what impact does it have on an individual child watching the show.

\section{Overview of Census Data}

Our main sources of individual-level data used to estimate equations (1) and (2) are microdata from the 1980, 1990, and 2000 U.S. Census of the Population, available from IPUMSUSA (Ruggles, et al., 2010). We restrict our Census samples to individuals born between 1959 and 1968; these individuals would have entered first grade from around 1965 until 1974 (depending on exact birthdates and state laws regarding age of school entry), just before and after Sesame Street was introduced.

Table 1 eases the interpretation of cohorts advancing through these censuses, indicating points in the lifecycle of those in the analysis sample as they age. First, we use the 1980 Census to examine elementary school performance as captured by "grade-for-age" status; this measure indicates whether a child is enrolled in school - or graduated high school for those over age 18 at a grade appropriate for his or her age. ${ }^{22}$ We use data on quarter of birth available in the 1980

\footnotetext{
${ }^{21}$ We have experimented with using an instrumental variables strategy to estimate this model with these restricted data - instrumenting for ratings with coverage - but the small sample size reduced the statistical power of the analysis to a point where it is not informative.

${ }^{22}$ Grade-for-age is an educational outcome that has been used by others, including Oreopoulos, Page, and Stevens (2006). It reflects a stock; falling behind could have taken place several years ago. Our analysis of data from the 1980 Census of those born between 1962 and 1974 (school-age at that time) indicates that many students fall behind
} 
Census along with the school entry requirement laws listed in Cascio and Lewis (2006) to refine our estimates of the year students would be expected to start school. ${ }^{23}$ The birth cohorts in our sample would be between the ages of 12 and 21 in the 1980 Census. Second, we use the 1990 Census to measure ultimate educational attainment (high school dropout, high school graduation, or attended any college), as these birth cohorts would be between ages 22 and 31 in 1990 (it is not possible in the 1990 Census to distinguish high school graduation from GED attainment). And third, we use the 2000 Census to measure labor market outcomes (employment, hourly wage, and poverty status) when these birth cohorts would have been between the ages of 32 and 41, presumably established in the labor market, if working.

An important issue to address regarding the use of Census data is migration. Ideally, we would know the state and county of residence in which an individual resided in 1969, when Sesame Street began, but this information is not available. For these birth cohorts, a reasonable alternative would exist if we knew the state and county of birth since they would all be very young in 1969 and mainly living in the same place. State of birth is, in fact, available in these Censuses, but county of birth is not.

To circumvent this problem we restrict our samples to those individuals whose recorded state of residence in the Census is the same as their state of birth. This sample restriction assumes that interstate mobility since birth is unrelated to Sesame Street coverage in 1969. For this subsample, we assign county of residence in the Census year to be the county of birth. The

in first through fourth grades. As Deming and Dynarski (2008) document, purposely holding children back from starting first grade at age six ("red-shirting") is a more recent phenomenon. Our data on grade-for-age status is consistent with that reported by Hauser (2004). Cascio (2005) indicates that grade-for-age is an imperfect proxy for grade repetition.

${ }^{23}$ Where necessary, we make the most generous assumptions possible to increase the likelihood of a child being in the appropriate grade level. For instance, a child born in the $3^{\text {rd }}$ quarter in a state where children are supposed to enter $1^{\text {st }}$ grade in September of the year they turn age 6 is treated as if he or she is still age 5 in that year; his or her birthday could have been in August. 
assumption that we maintain in this assignment is that individuals who live in the same state where they were born are likely to remain in a county close to where they were born and, importantly, in the same television market with similar broadcast reception.

Table 2 provides some evidence suggesting that our sample decisions regarding migration are reasonable. For this purpose, we first examine mobility data from the Census and compare it to the 1979 National Longitudinal Survey of Youth (NLSY79), which provides more geographic detail. Respondents in the NLSY79 were born between 1957 and 1964, comparable to the birth cohorts we examine with Census data (1959 to 1968). First, we explore interstate mobility between birth and 1980, 1990, and 2000 using the Census, and then using NLSY79 interstate mobility between birth and the same years. The results in Table 2 provide evidence indicating interstate mobility in the Census and NLSY79 are quite comparable; around 77 percent, 67 percent, and 65 percent of respondents lived in the same state in 1980, 1990, and 2000, respectively, in the two datasets. If we restrict the NLSY79 sample in each year to those who lived in the same state as they were born, we also see that over 80 percent lived in a county within 60 miles of their birth county.

We also used the NLSY79 data to estimate regression models comparable in format to that described by Equation (1) except that the dependent variable is an indicator of state outmigration. The results reported in the bottom panel of Table 2 do not provide evidence of selective state outmigration between birth and 1980 or 1990 . Those young enough to have seen Sesame Street when it first came out in areas where more residents could see it are not significantly differentially likely to live in a state different from where they were born. We also find no evidence of a relationship between Sesame Street exposure and movement to a county outside a 60 mile radius from the county of birth for those who never left their home state. Those 
who did move, however, will generate some attenuation bias in our Census analysis resulting from measurement error in Sesame Street exposure. We will address this issue further when we describe the results of our analysis.

Using Census data to estimate our equations of interest requires one additional sample restriction. County of residence is only identified for those individuals in sufficiently heavily populated counties. This eliminates roughly half the sample. Those included in the 1980 Census live in just 349 counties, for instance. The location of these counties is documented in Figure 4, which demonstrates the focus on more heavily populated areas.

A beneficial result of this data constraint is that identification in our statistical model is not driven by comparisons of urban and rural locations. In fact, using data from the 1970 Census, we show in Table 3 that among counties with available data in the 1980 Census, those distinguished by the quality of reception are generally quite similar both in 1970 and in changes since $1960 .{ }^{24}$ Those counties not in the sample are quite a bit smaller and poorer than the others. This makes sense since the reason they are not separately identified is because they are too small, and, at the time, rural poverty was an even greater issue. Differences, though, between strong and weak reception counties (defined below) among those separately identified are rather limited; ttests comparing them are unable to distinguish the observed differences from random variation. Certainly this analysis does not prove that these groups are randomly selected, but it does indicate that no obvious selection differentiates these two sets of counties.

\section{RESULTS}

\section{A. Graphical Analysis}

\footnotetext{
${ }^{24}$ These data come from the 1962 and 1972 County and City Data Book, which is available from ICPSR.
} 
Before presenting our formal results from estimating Equations (1) and (2), we first present Figures 5 through 8, which are designed to illustrate our identification strategy and guide the interpretation our subsequent findings. For this analysis, we distinguish counties by their distance to the closest tower broadcasting Sesame Street and whether that broadcast was UHF or VHF. We define "strong reception" counties to be those within 60 miles of one of those towers and broadcasting in VHF. All other counties are defined to be "weak reception" counties because they violated at least one of those conditions. Based on our estimated coverage rates and data from the 1980 Census, these categories roughly split our sample in half, with coverage rates of 83 and 55 percent, on average, in strong and weak reception counties.

We then trace out differences in our outcome measures (grade-for-age status, educational attainment, and labor market outcomes) by exact cohort between those who live in strong and weak reception areas. This approach mimics a simplified reduced form version of the analysis we report below. Here we aggregate counties' reception capabilities rather than use them continuously in our full econometric analysis.

Figure 5 compares grade-for-age status across these categories for several birth year cohorts. The horizontal axis is distinguished by cohort and is designed to identify those who may have been affected by Sesame Street's introduction. In the 1980 Census, quarter of birth data is available and we use that to better determine school start year. In other Census years, we rely on the year a child turned age 6. If Sesame Street had an effect on educational or labor market outcomes, we would expect to the see the effect for the birth cohorts who started school (in the 1980 Census) or turned 6 (in the 1990 and 2000 Census) in 1970 or later. These children would have been preschool age when the show was introduced. Those who started school or were older 
than age 6 in 1968 or earlier would not have been as directly affected by its introduction, since the show targets preschool age children and academic skills most relevant to school entry.

We view those individuals who were supposed to start school in 1969 - those who were typically age 6 at the time - as a transitional cohort. Although a show designed to improve first grade readiness should not have a large impact among those who were already in first grade, some children in this cohort may not have started school yet. Others may have started school, but were not doing well in first grade. Since Sesame Street was shown in most locations during after school hours, these students may have benefited from its availability as well. We do not expect any effect on them to be as large as for the younger cohorts, but we recognize the possibility of an intermediate effect.

The results of this simple analysis regarding grade-for-age status reported in Figure 5 support the hypothesized patterns. For cohorts who should have started school in 1968 and earlier, there is not a large difference in grade-for-age status between those in stronger versus weaker reception counties. For cohorts who should have started school in 1970 and later, there is a clear positive difference in rates of grade-for-age between those in the two areas. As a whole, those in the strong reception counties are 1.5 to 2 percentage points more likely to be at the grade level appropriate for their age in 1980. Differences in grade-for-age status for the 1969 school start year cohort are positive, but smaller than those for subsequent cohorts, as expected. Overall, this figure provides evidence supportive of an effect on grade-for-age brought about by exposure to Sesame Street.

We extend this analysis to consider whether the show's impact is greatest among more disadvantaged children. As we described earlier, however, we do not have a good way to measure socioeconomic status in the census data available to us. Instead, we augment the census 
data with additional data from the 1970 Census distinguishing locations by different levels of disadvantage. This approach focuses on the relative disadvantage of an area, not the individual. In this analysis, we focus on the percentage of the county population that has less than a high school degree, splitting counties by those that are above and below the median value. ${ }^{25}$ The results of this analysis, reported in Figure 6, indicate that the impact of Sesame Street's introduction on grade-for-age status is considerably greater in more disadvantaged areas. Cohorts who were of pre-school age at the time the show began were roughly 3 percentage points more likely to be at the appropriate grade level for their age if they lived in an area with strong reception. This is perhaps twice the estimated effect for the population as a whole.

The results regarding educational attainment and labor market outcomes, reported in Figures 7 and 8, are less compelling. We chose the likelihood of graduating high school (including those who attend college) as our indicator of educational attainment and the percentage of the population that is employed (the "employment rate") as our indicators of labor market performance. In neither case is there anything resembling a positive break from trend around the 1969 school entry cohort, defined by the year a child turned age 6 .

\section{B. Econometric Results: Grade-for-Age}

Table 4 presents our estimation results reflecting the models represented by Equations 1 and 2 above. For the full sample, from the top panel of the table, reporting results from estimating Equation 1, we find that children who were preschool age in 1969 and who lived in areas with greater simulated Sesame Street coverage were statistically significantly more likely to be at the grade level appropriate for their age. To interpret the magnitude of the coefficient, we

\footnotetext{
${ }^{25}$ In subsequent analyses, we also use these data to distinguish counties by the percentage of families headed by a female head, the percentage of families with incomes below $\$ 5,000$ in 1970, and the percentage of the population that is black. Results for the present analysis using high and low values of these other measures are comparable to those reported here.
} 
consider the impact of a 30 percentage point increase in coverage rates, which is tantamount to moving from a typical area with weak reception to an area with strong reception. The hypothetical case of moving from no coverage to complete coverage is out of sample and thus an inappropriate basis of comparison. A 30-point increase in coverage rates would generate a 3.2 percentage point $\left(0.3^{*} 0.105=0.032\right)$ increase in the rate of grade-for-age. With 20.3 percent of the sample behind their appropriate grade in school, this estimate implies that moving from a weak to strong reception county would lower that rate by around 16 percent. ${ }^{26}$

This effect on grade-for-age status is particularly pronounced among boys. The estimated effect is largest (in absolute terms) for black, non-Hispanic children, but the estimated coefficients are not statistically significantly different across race/ethnic groups. For boys, gradefor-age status is estimated to jump 3.8 percentage points $(0.128 * .3)$ between weak and strong reception counties. This reflects a similar 16 percent reduction in the likelihood of being below grade level, because this is one of the groups that has the most room for improvement in gradefor-age status. For black, non-Hispanics, grade-for-age status is similarly estimated to jump by 3.2 percentage points $\left(0.105^{*} .3\right)$, which reflects a 10.8 percent reduction in being behind in school. The impact for white, non-Hispanics is still sizable; grade-for-age status is estimated to rise by 2 percentage points $\left(.068^{*} .3\right)$, reducing the dropout rate by 11.9 percent. Coefficient estimates by gender are significantly different from each other.

As a point of comparison, Currie and Thomas (1995) report estimates from sibling difference models indicating that white children are 47 percent less likely to repeat a grade if they attended Head Start relative to a sibling who did not. They did not find a statistically

\footnotetext{
${ }^{26}$ The fact that this estimate is somewhat larger than what one would expect from Figure 5 is attributable to including state*birth cohort fixed effects. In a more traditional difference-in-difference analysis including birth cohort and county fixed effects, our results are very similar to what we observe in Figure 5.
} 
significant effect for African-Americans. We find that white and black children who were age 5 or younger when Sesame Street was introduced and who lived in an area with strong reception were 8.3 and 13.7 percent, respectively, less likely to be below the grade level appropriate for their age relative to children in weak reception areas. Recall that coverage rates are 28 percent higher in strong reception areas than in weak reception areas ( 83 versus 55 percent). For purposes of comparison we simulate what would happen if we moved from no coverage to complete coverage (admittedly an out-of-sample prediction). This generates the prediction that the rate of being behind grade-level in school falls 29.6 percent for white, non-Hispanics and 49 percent for black, non-Hispanics. These results suggest that the introduction of Sesame Street for white and black, non-Hispanic children had similar effects on elementary school performance as did participation in the Head Start program. ${ }^{27}$

The bottom panel of the table reports the results of the more descriptive model in Equation 2. To obtain more power, we aggregate birth cohorts into two year intervals. Because we want the interaction between coverage and the 1969 school start year cohort to enter the model separately as a possible transition year, we move 1970 to form a 1970 through 1972 aggregated birth cohort. Again, the results of this analysis strongly correspond to the patterns reported in Figure 5. For those scheduled to start school prior to 1969, we see no significant difference in outcomes. For those cohorts that started school in 1970 and afterwards, we see a

27 We also perform a simple simulation exercise to compare the size of our grade-for-age effects with the PPVT findings of Bogatz and Ball (1970). To do this, we used data from the National Longitudinal Survey of Youth (1979) to regress grade-for-age status at ages 15 and 16 on PPVT scores at ages 3 to 5, controlling for mother's education, race/ethnicity, and sex. This regression suggests that a one-point increase in PPVT scaled score increases the likelihood of being grade for age by 0.22 percentage points. Recall that Bogatz and Ball (1979) found that exposure to Sesame Street increases PPVT scores by 0.36 of a standard deviation, or 5.4 points in the scaled score. Based on the simple NLSY regression, a 5.4 point increase in PPVT scaled score would increase GFA by $(5.4 * 0.22) 1.2$ percentage points. Our main estimates indicate that a 30 percent increase in Sesame Street coverage increased the likelihood of being grade-for-age by $(0.097 * 3) 2.9$ percentage points. This seems to suggest that the impact of Sesame Street on educational progress goes beyond what we would expect just from improved PPVT. We think this is intriguing, but given its crudeness, we are not inclined to make too much of this comparison. 
statistically significant (at least at the 10\% level) increase in grade-for-age status associated with greater Sesame Street coverage. For the 1969 school start year cohort, we see an effect between the younger and older groups, as hypothesized. These results support the interpretation of a causal effect. Again, the estimated impact is particularly large for boys, and the point estimates suggest for black, non-Hispanic children.

We extend this analysis to consider whether the show's impact is greatest among children from more disadvantaged areas. To do this, we augment the census data with additional data from the 1970 Census obtained from the 1972 County and City Databook, which distinguishes locations by different levels of disadvantage. This approach focuses on the disadvantage of the area, not the individual. The indicators we use are the percentage of the county population that has less than a high school degree, the percentage of families headed by a female head, the percentage of families with incomes below $\$ 5,000$ in 1970 , and the percentage of the population that is black. The top row of Table 5 indicates mean values for these indicators.

The remainder of Table 5 presents regressions results that are largely of the same form as Equation 1, except that they also introduce an additional interaction term between a measure of county-level economic disadvantage and the indicator variable for those who would be of preschool age after 1969 in counties with different predicted Sesame Street coverage rates. ${ }^{28}$ In each case, we find that the ability of Sesame Street to increase the rate at which children are at grade level is greater in areas characterized by greater disadvantage. For instance, a county where two-thirds of the households are headed by high school dropouts (compared to the mean

\footnotetext{
${ }^{28}$ The reader should note that this is a restricted version of a more general triple-difference estimation strategy, as described in Gruber (1994). The main difference is that our model restricts the coefficients on the interactions between cohort fixed effects and county characteristics to be zero. When we relax this restriction, we find that our data are not sufficiently powerful to separately identify all of the effects without a sizable impact on the standard errors of our variables of interest. With the restriction imposed, bias would result if children from more disadvantaged counties experienced differential educational outcomes well-timed to the introduction of Sesame Street. This is an unlikely, but not impossible scenario.
} 
rate of 44.6 percent) would experience about a 5.8 percentage point increase in grade-for-age status if Sesame Street coverage rose from a low level to a high level [0.3*(66.7*.0046-.115)]. This compares to the average effect of 3.2 percentage points calculated earlier.

\section{Econometric Results: Educational Attainment and Labor Market Outcomes}

We now move on to consider later life outcomes, including ultimate educational attainment and labor market outcomes. We estimate completely analogous models to those reported earlier other than changing the dependent variable and the specific Census data on which we estimate the models. The measures of educational attainment (high school dropout, high school graduate, or attending any college) come from the 1990 Census. Measures of labor market outcomes (log hourly wage, employment status, and poverty status) come from the 2000 Census.

The results of this analysis are reported in Table 6; the top panel reports models of the form represented in Equation (1) and the lower panel breaks out these effects by specific birth cohort, as described by Equation (2). Estimates are reported for each educational attainment and labor market outcome for the full sample (each cell represents the results from a separate regression). The results in the first three columns regarding educational attainment provide no evidence of changes in these outcomes. Parameter estimates are small, statistically insignificant, and inconsistent with the expected pattern across cohorts (in the bottom panel). ${ }^{29}$

\footnotetext{
${ }^{29}$ The lack of any impact on educational attainment may be considered surprising in light of the positive effect on grade-for-age status that we identified earlier. However, whether a student falls behind in school at a young age does not have a very strong predictive relationship with whether he or she ultimately graduates high school. To formalize the strength (or lack thereof) of the relationship between grade-for-age status in 1980 with educational attainment in 1990, we collapsed data from the two Censuses to generate rates of each type of outcome by birth cohort and state and county of birth (noting our earlier discussion regarding geographic distinctions in the data). The correlation coefficient between rates of grade-for-age status in 1980 with the high school dropout rate in 1990 for the same birth cohort is -0.44 . This is a substantial correlation, but also makes clear the possibility that Sesame Street may have improved grade-for-age status without reducing the subsequent high school dropout rate for the same cohort.
} 
The results in the last three columns regarding labor market outcomes are less clear. Parameter estimates all take on the expected signs (positive for employment and wages, negative for living in poverty). The estimated impact on employment is statistically significant at the 5 percent level and the other two estimates are just above and below the threshold of statistical significance at the 10 percent level. Following cohorts, the estimated effects reveal the predicted patterns as shown in the bottom of the table and the employment effects are statistically significant for the preschool cohorts in 1969.

The magnitude of these effects, though, is small. ${ }^{30}$ Our standard for interpreting magnitudes has been to evaluate the impact of moving from a weak reception county to a strong reception county, characterized by a 30 point increase in coverage. These results predict that employment would rise by about one percentage point $(0.3 * 0.034)$. Similarly, wages would be predicted to rise by 0.93 percent $(0.3 * 0.31$; note that wages are measured in natural logs).

Perhaps we should not expect to see large labor market effects driven by early childhood exposure to Sesame Street. To put these small estimated magnitudes into context, we consider what we might have expected to see given the magnitude of effects on early childhood test scores and grade-for-age status. To pursue this simulation exercise, we relate gains in test scores and grade-for-age status to wages, and then multiply this relationship by the estimated effects of Sesame Street on these two measures. Previous estimates suggest that a 0.1 standard deviation increase in reading test scores is associated with a 0.6 percent wage increase (Levine and

\footnotetext{
${ }^{30}$ One potential concern with the longer term estimates for educational attainment and labor market outcomes as compared to the grade-for-age results is the possibility of greater attenuation bias in the 1990 and 2000 Censuses than in the 1980 Census. In the mobility results we reported in Table 2 using the NLSY, this would appear in the greater likelihood of a more distant inter-county move within states over time (attenuation bias in interstate mobility is not an issue based on our decision to examine just those who live in the same state as they were born). We used those data to simulate what would happen if 5.3 percent of the sample moved out of the area around their county of birth and we re-assigned them randomly to other locations. This amount is the difference in inter-county mobility observed between 1980 and 2000. The impact on our point estimates was minor, implying that greater attenuation bias cannot explain the stronger results in grade-for-age status than in educational or labor market outcomes.
} 
Zimmerman, 2010). ${ }^{31}$ The estimates from Bogatz and Ball (1971) indicate that Sesame Street increased reading test scores of viewers by 0.36 standard deviations. Our simulation is based on a 30 percentage point increase in exposure associated with greater reception. This would generate a prediction of a 0.65 percent $(0.3 * 0.36 * 0.6)$ increase in wages. This is actually somewhat smaller than what we observe in the wage data.

To consider what our estimated effects on grade-for-age status would imply, we need to document the relationship between this outcome and wages. Using data from the 1979 National Longitudinal Study of Youth (NLSY), we regress the natural log of wages in 2010 on grade-forage status in 1979 among those born in 1962-1964 (who should still be in school in 1979), controlling for race/ethnicity, gender, living arrangements, and parental education. The results indicate that students who are in the appropriate grade in high school earn 27 percent more than those who are behind. Our analysis of 1980 Census data, reported earlier, indicates that those in strong reception areas are 3 percentage points more likely to be in the appropriate grade relative to those in weak reception areas. This suggests we should find a 0.81 percent increase in wages associated with living in a strong reception area. This is in the same vicinity as the wage effect that we estimated.

What we can conclude from this analysis is that the results do not provide strong evidence of substantive improvements in labor market outcomes. This is not to say that exposure to Sesame Street had no effect; the fact that we are not able to strongly distinguish our estimates from zero may reflect limited power, even using large Census samples.

\footnotetext{
${ }^{31}$ Based on a review of past studies estimating the relationship between test scores and wages, Krueger (2003) concludes that "a plausible assumption is that a one SD increase in either math or reading scores in elementary schools is associated with about 8 percent higher earnings." The estimate we use is similar to this, but it is likely more relevant since it is based on test scores at young ages in an American context (using the NLSY), which is not true of the other studies.
} 


\section{Analysis of High School ANd Beyond Data}

One limitation of our analysis so far is that it cannot capture specific mechanisms that have been explored more recently in thinking about longer-term effects of educational interventions (cf. Heckman, 2006). Interventions may be effective in improving narrower measures of academic achievement (“cognitive outcomes") and/or improving a child's level of socio-emotional development (sometimes referred to by economists as "non-cognitive outcomes"). Census data do not allow us to distinguish between these types of intermediate outcomes because no measures of non-cognitive outcomes are available.

To overcome this limitation, we augment the analysis above with an analysis of data available in the longitudinal survey, High School and Beyond (HSB). These data are obtained from a school-based survey of around 60,000 students who were high school sophomores and seniors in 1980. This data source contains extensive data on a range of outcomes including test scores, school grades, and self-reported measures of self-esteem and locus of control. In our analysis below, we have standardized test scores, measures of self-esteem, and locus of control so that each has a mean of zero and a standard deviation of one. The National Center for Educational Statistics (NCES) in the U.S. Department of Education does not provide access to any geographic identifiers with HSB data, not even with a restricted use agreement. However, a contextual file is available through ICPSR that provides details regarding county level unemployment rates, employment growth rates, and the like. We make use of those data to reverse engineer the HSB data to identify the county locations of the school. Data Appendix 2 describes the procedure we used.

There are two cohorts of students in the HSB data who would have entered first grade right before and after the introduction of Sesame Street. High school seniors in the spring of 
1980 who advanced on target through the educational system mainly would have been born in 1962; sophomores would have been born in 1964. This provides the possibility of within-school controls since sophomores, but not seniors, would have been exposed to Sesame Street before starting first grade. Comparing the two groups across areas that differ by Sesame Street coverage rates provides a plausible method of identifying the effects of the show.

Despite the significant advantages of these data for our purposes, they do possess some limitations. First, as suggested by earlier discussions in this paper, a substantial minority of students do not advance through the educational system on pace with their birth cohort. Many students will have fallen behind by tenth grade. This weakens the experimental design because those sophomores who had fallen behind may have been born before 1964 and, thus, would not have been exposed to Sesame Street before entering school. This amounts to a contamination of the treatment, introducing a bias towards zero in our analysis.

A second limitation is generated because the school-based nature of the data omits those students who had dropped out already. Although dropout rates prior to $10^{\text {th }}$ grade are reasonably rare, by $12^{\text {th }}$ grade they are not. As such, sample selection plagues the control group in a way that is not replicated in the treatment group. To address this problem, we restrict our sophomore sample to those who begin their senior year two years later in 1982, making for a fair comparison between the remaining sophomores and seniors. It does, however, restrict the scope of our analysis to those who survive the educational system through the end of high school. We also find that very few students who make it to twelfth grade fail to graduate high school. Despite these limitations, the HSB data provide a useful opportunity to examine specific intermediate outcomes, and we proceed accordingly. 
The results of our analysis are reported in Table 7. The top panel focuses on measures of $12^{\text {th }}$ grade academic achievement, including test scores in math, vocabulary, and reading, along with high school grades (an indicator for receiving mostly A's and B's in school). The bottom panel focuses on measures of socio-emotional development, including locus of control, selfesteem, behavior problems, and work ethic measured in each cohort's senior year. We estimate IV models comparable in form to those described earlier using Census data, though we include school fixed effects, rather than county fixed effects, in this specification. The key explanatory variable is the interaction between the predicted coverage rate in one's county with cohort (sophomore or senior in the initial survey). We also include state by cohort fixed effects and a series of other explanatory variables, which include basic demographics along with greater detail on socioeconomic status, like family income.

The results from this analysis do not support the conclusion of an impact of watching Sesame Street on academic of socio-emotional development by the end of high school for these students. Although some of the outcomes are estimated to improve for the treated group (sophomores) with higher coverage rates, these effects are generally not statistically significant (the effect on self-esteem is significant at the 10 percent level). This finding is not the result of low power. Consider, for instance, the estimated impact on math test scores, which has a standard error of 0.060 . We would be able to reject the null hypothesis of no effect if the coefficient was around 0.12 at the 5 percent level. This coefficient would indicate that moving from a low coverage state to a high coverage state would increase math test scores of the exposed cohort (sophomores in 1980) by 0.036 of a standard deviation. One potential interpretation is that any effect of the show in either dimension had completely faded by the time one reached the latter stages of his or her high school career. 


\section{DISCUSSION}

This paper has documented the effects of exposure to Sesame Street programming content on indicators of early school performance, ultimate educational attainment, and labor market outcomes. Well-conducted randomized control trials at the time Sesame Street was initially introduced provided evidence that watching the show generated an immediate and sizeable increase in test scores. Building on this existing body of early, targeted evidence, our large-scale analysis finds positive impacts on the educational performance of the generation of children who experienced their preschool years when Sesame Street was introduced in areas with greater broadcast coverage. Specifically, such children achieved relative increases in grade-forage status. This outcome largely represents improvements in academic progress in elementary school, when students at that time were more likely to fall behind their appropriate grade level. This effect was particularly pronounced for boys and black, non-Hispanic children, along with those children who grew up in counties characterized by greater economic disadvantage. In that regard, Sesame Street satisfied its goal of preparing children for school entry, especially for black and disadvantaged children. ${ }^{32}$ Remarkably, the show accomplished that at a cost of around $\$ 5$ per child per year (in today's dollars).

The data do not provide conclusive evidence of longer-term effects on ultimate educational attainment or labor market outcomes. As described earlier, though, the small effects on wages are consistent with the magnitude of our estimated effect of Sesame Street on grade-

\footnotetext{
${ }^{32}$ Recent research has also explored the ability of newer educational programming (Martha Speaks, Super Why!, and others) developed by the Corporation for Public Broadcasting to improve test scores of preschool and kindergarten students in random assignment experiments (Linebarger, et al., 2009 and 2010). These analyses also find sizeable effects of viewing the shows. None of these interventions have been going on long enough to examine long-term outcomes.
} 
for-age status, as well as earlier estimates of the impact of the show on early childhood test scores.

What then could help boost that impact to produce substantive effects beyond elementary school? Although our analysis does not address this question, we offer two possibilities. From the academic side, interventions that are longer-lasting in nature may help. Again, exposure to Sesame Street represents a one-time intervention with nothing intentional to follow. Students reach $1^{\text {st }}$ grade better able to begin a reading curriculum, for instance, but at some point all students will have accomplished that goal. One interpretation of weak longer-term effects is that educational interventions need to be maintained and continuous so that students can build on the gains they have already attained to keep the momentum going. ${ }^{33}$

Alternatively (or in addition), perhaps more emphasis needs to be concurrently placed on socio-emotional development and academic skills. Among the types of early childhood education interventions that were introduced during this period in the late 1960s (including Head Start and Perry Preschool), Sesame Street was perhaps the most narrowly targeted at the objective of improving educational achievement at its origin. This targeting is clear in the original stated objectives of the show (Cooney, 1967). Those objectives go beyond only an emphasis on academic achievement, incorporation of cultural development (arts and music) and awareness of basic emotions, but their broader focus on socio-emotional development is rather limited. ${ }^{34}$ Other interventions at that time and those introduced in the intervening years (including universal prekindergarten) contain far greater emphasis on both academic achievement and socio-emotional development.

\footnotetext{
${ }^{33}$ Regarding MOOCs, an intervention like Khan Academy has that potential, for instance, to satisfy this concern, since it is not just a one-time intervention in a specific school grade.

${ }^{34}$ Over time, Sesame Street has broadened its focus to include greater emphasis on socio-emotional development (Davis, 2008), but those changes are not assessed here.
} 
The role played by socio-emotional development is frequently emphasized in research regarding the impact of early childhood education, including that on Head Start, Perry Preschool, and Project Star (cf. Carneiro and Heckman, 2005, and Chetty, et al., 2011). Interventions that do not emphasize the importance of this form of development may be limited in their ability to generate long-term effects. If so, then perhaps a blended learning environment incorporating both electronic communication of educational content and the human element to affect the "soft skills" may be preferable, and cost-effective. An understanding of the importance of these (or potentially other) alternatives is critical in designing future efforts to improve subsequent economic circumstances through early childhood education. As research and policy discussions continue to focus on early childhood education, the results of this analysis suggest that the impact of Sesame Street deserves to be included along with Perry Preschool, Head Start and other programs. 


\section{References}

Akanegbu, Anuli (2013). "Does the Khan Academy Pass the MOOC 'Duck Test'?" EdTech. http://www.edtechmagazine.com/higher/article/2013/04/does-khan-academy-pass-mooc-ducktest (accessed 2/9/2015).

Bogatz, Gerry Ann and Samuel Ball (1971). The Second Year of Sesame Street: A Continuing Evaluation. Princeton, NJ: Educational Testing Service.

Brown, Les (1969). “ 'Sesame Street’ Dazzles in Television Premiere.” Variety. December 24.

Carneiro, Pedro and James J. Heckman (2005). "Human Capital Policy," in James J. Heckman and Alan B. Krueger (eds.), Inequality in America: What Role for Human Capital Policies? Cambridge, MA: MIT Press.

Cascio, Elizabeth U. (2005). "School Progression and the Grade Distribution of Students: Evidence from the Current Population Survey.” IZA Discussion Paper 1747.

Cascio, Elizabeth U. and Ethan G. Lewis (2006). "Schooling and the Armed Forces Qualifying Test: Evidence from School-Entry Laws.” The Journal of Human Resources, 41(2): 294-318.

Cascio, Elizabeth U. (2009). Do Investments in Universal Early Education Pay Off? Long-Term Effects of Introducing Kindergartens into Public Schools. NBER Working Paper 14951.

Cascio, Elizabeth U. and Diane Whitmore Schanzenbach (2014). "Expanding Preschool Access for Disadvantaged Children" in Melissa S. Kearney and Benjamin H. Harris (eds.), Policies to Address Poverty in America. Brookings Institution: Washington, DC.

Chetty, Raj, John Friedman, Nathaniel Hilger, Emmanuel Saez, Diane Schanzenbach, and Danny Yagan (2011). "How Does Your Kindergarten Classroom Affect Your Earnings? Evidence from Project STAR.” Quarterly Journal of Economics 126(4): 1593-1660.

Children's Television Workshop (undated). "First Season Broadcast Times by Station 19691970" Box 33, Folder 13. Children's Television Workshop Collection. Special Collections in Mass Media \& Culture. University of Maryland Libraries.

Clausen, Ralph T. (1970). Letter to Paul Klein of National Broadcasting Company, February 17. Box 44, Folder 19. Children's Television Workshop Collection. Special Collections in Mass Media \& Culture. University of Maryland Libraries.

Council of Economic Advisers (2015). The Economics of Early Childhood Investments. Washington, DC: Executive Office of the President. Available at:

https:/www.whitehouse.gov/sites/default/files/docs/early_childhood_report_update_final_nonembargo.pdf (accessed 5/11/2015).

Cook, Thomas D., Hilary Appleton, Ross F. Conner, Ann Shaffer, Gary Tamkin, and Stephen J. Weber (1975). "Sesame Street” Revisited. New York: Russell Sage Foundation. 
Cooke, Robert (1965). "Recommendations for a Head Start Program.” Washington, DC: U.S. Department of Health, Education, and Welfare, Office of Child Development. Available at: https://eclkc.ohs.acf.hhs.gov/hslc/tta-system/health/health-services-management/programplanning/Cooke\%20Report.pdf (accessed 1/27/2015).

Cooney, Joan Ganz (1967). The Potential Uses of Television in Preschool Education (Report to the Carnegie Corporation of New York). Available at:

http://www.joanganzcooneycenter.org/wp-content/uploads/2014/01/JGC 1966 report.pdf (accessed 1/28/2015).

Currie, Janet and Duncan Thomas (1995). “Does Head Start Make a Difference?" American Economic Review, 85(3): 341-364.

Davis, Michael (2008). Street Gang: The Complete History of Sesame Street. New York: Penguin Books.

Deming, David and Susan Dynarski (2008). "The Lengthening of Childhood." Journal of Economic Perspectives, 22(3): 71-92.

Diaz-Guerrero, Rogelio, Isabel Reyes-Lagunes, Donald B. Witzke, and Wayne H. Holtzman (1976). "Plaza Sésamo in Mexico: An Evaluation." Journal of Communication, 26(2): 145-154.

Duncan, Greg J. and Katherine Magnuson (2013). "Investing in Preschool Programs." Journal of Economic Perspectives. 27(2): 109-132.

Fisch, Shalom M. and Rosemarie T. Truglio (2001). G Is for Growing: Thirty Years of Research on Children and Sesame Street. New Jersey: Lawrence Erlbaum Associates.

Gentzkow, Matthew and Jesse M. Shapiro (2008). "Preschool Television Viewing and Adolescent Test Scores: Historical Evidence from the Coleman Study". Quarterly Journal of Economics 123(1): 279-323.

Gibbs, Chloe, Jens Ludwig, and Douglas Miller (2013). "Head Start: From Origins to Impacts?" in Martha Bailey and Sheldon Danziger (eds.), Legacies of the War of Poverty. New York: Russell Sage Foundation.

Hart, Cassandra Elizabeth Friedmann, and Michael Hill (2015). "Online Course-taking and Student Outcomes in California Community Colleges." UC Davis manuscript.

Gruber, Jonathan, "The Incidence of Mandated Maternity Benefits," The American Economic Review 84:3 (1994), 622-641.

Hauser, Robert M. (2004). "Progress in Schooling," in Kathryn M. Neckerman (ed.), Social Inequality. New York: Russell Sage Foundation. 
Haydon, M. (1973). "Draft Report on Audience Data," Commissioned by CTW to study audience for Sesame Street and Electric Company." Box 44, Folder 32. Children's Television Workshop Collection. Special Collections in Mass Media \& Culture. University of Maryland Libraries.

Heckman, James J. (2006). "Skill Formation and the Economics of Investing in Disadvantaged Children.” Science, 312(5782): 1900-1902

Hill, C.J., Bloom, H.S., Black, A.R., and Lipsey, M.W. (2008). "Empirical Benchmarks for Interpreting Effect Sizes in Research." Child Development Perspectives, 2(3):172-177.

Hoynes, Hilary W., Diane Whitmore Schanzenbach, and Douglas Almond (2012). "Long Run Impacts of Childhood Access to the Safety Net.” NBER Working Paper No. 18535.

Hunt, J. McVicker (1961). Intelligence and Experience. New York: John Wiley and Sons.

Jensen, Robert and Emily Oster (2009). "The Power of TV: Cable Television and Women's Status in India." Quarterly Journal of Economics. 124(3): 1057-1094.

Kearney, Melissa Schettini and Phillip B. Levine. "Media Influences on Social Outcomes: The Impact of MTV's 16 and Pregnant on Teen Childbearing." National Bureau of Economic Research Working Paper 19795, January 2014.

Krueger, Alan B. (2003). "Economic Considerations and Class Size." Economic Journal, 113(485): F34-F63.

Levine, Phillip B. and David J. Zimmerman (2010). "Synthesizing the Results," in Phillip B. Levine and David J. Zimmerman (eds.), Targeting Investments in Children: Fighting Poverty When Resources are Limited. Chicago, IL: University of Chicago Press.

Linebarger, Deborah L., Katie McMenamin, K. \& Deborah K. Wainwright (2009). Summative Evaluation of 'Super Why!': Outcomes, Dose and Appeal. Philadelphia, PA: Annenberg School for Communication, University of Pennsylvania.

Linebarger, Deborah L., Annie M. Moses, and Katie McMenamin (2010). Vocabulary Learning From Educational Television: Can Children Learn New Words From 'Martha Speaks'? Philadelphia, PA: Annenberg School for Communication, University of Pennsylvania.

Ludwig, Jens and Douglas L. Miller (2007). "Does Head Start Improve Children's Life Chances? Evidence from a Regression Discontinuity Design." Quarterly Journal of Economics, 122(1): 159-208.

Luzer Daniel (2014), "Does Khan Academy Work?" http://www.washingtonmonthly.com/college_guide/blog/does_khan_academy_work.php (accessed 1/27/2015). 
Marcus, Jon (2013). “All Hail MOOCs! Just Don’t Ask if They Actually Work.” http://nation.time.com/2013/09/12/all-hail-moocs-just-dont-ask-if-they-actually-work/ (accessed 1/27/2015).

McDowell, Walter S. (2006). Broadcast Television: A Complete Guide to the Industry. New York: Peter Lang Publishing, Inc.

Olken, Benjamin A (2009). "Do Television and Radio Destroy Social Capital? Evidence from Indonesian Villages." American Economic Journal: Applied Economics, 1(4): 1-33.

Oreopoulos, Philip, Marianne E. Page, and Ann Huff Stevens (2006). "The Intergenerational Effects of Compulsory Schooling.” Journal of Labor Economics, 24(4): 729-760

Paulson, F. Leon (1974). "Teaching Cooperation on Television: An Evaluation of Sesame Street Social Goals Programs." AV Communication Review, 22(3): 229-246.

Rothenberger, Cecilia (2004). "The UHF Discount: Shortchanging the Public Interest." American University Law Review, 53(2): 689-729.

Ruggles, Steven J., Trent Alexander, Katie Genadek, Ronald Goeken, Matthew B. Schroeder, and Matthew Sobek. (2010) Integrated Public Use Microdata Series: Version 5.0 [Machinereadable database]. Minneapolis: University of Minnesota.

Shager, Hilary M., Holly S. Schindler, Katherine A. Magnuson, Greg J. Duncan, Hirokazu Yoshikawa and Cassandra M. D. Hart (2013). "Can Research Design Explain Variation in Head Start Research Results? A Meta-Analysis of Cognitive and Achievement Outcomes." Educational Evaluation and Policy Analysis, 35(1): 76-95.

Sinha, Shantanu (2011). "Does Khan Academy Really Work?"

http://www.huffingtonpost.com/shantanu-sinha/does-khan-academy-really-_b 946969.html (accessed 1/27/2015).

Stevens, Katherine B. (2015). "Early Childhood Education: Worth Doing - and Worth Doing Right," in American Enterprise Institute (ed.) Education in America and How to Improve it. Washington, DC: American Enterprise Institute.

Television Digest, Inc. (1968-1969). Television Factbook: Stations Volume. Washington, DC: Television Digest, Inc. available at: http://www.americanradiohistory.com/Archive-BC-

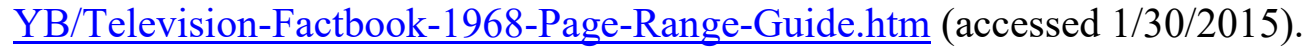

TV Guide (1966). TV Set Buyer's Guide. Available at:

http://www.bretl.com/tvarticles/documents/TVGuide1966BuyersGuide.pdf

(accessed 1/29/2015).

U.S. Bureau of the Census (1968), Statistical Abstract of the United States. Washington, DC: Government Printing Office. 
U.S. Bureau of the Census (1970), Statistical Abstract of the United States. Washington, DC: Government Printing Office.

U.S. Bureau of the Census (1974). Centers of Population for States and Counties. Washington, DC: Government Printing Office.

Webbink, Douglas W. (1969). "The Impact of UHF Promotion: the All-Channel Television Receiver Law." Law and Contemporary Problems, 34 (3): 535-561.

Zigler, Edward and Susan Muenchow (1994). Head Start: The Inside Story of America's Most Successful Educational Experiment Paperback. New York: Basic Books. 
Table 1: Aging Patterns by Birth Cohort

\begin{tabular}{cccccc}
\hline \multicolumn{5}{c}{} & \multicolumn{5}{c}{ Anticipated } \\
Year of Birth & Year Age 6 & Age in 1980 & Grade in 1980 & Age in 1990 & Age in 2000 \\
\hline 1959 & 1965 & 21 & HS Grad & 31 & 41 \\
1960 & 1966 & 20 & HS Grad & 30 & 40 \\
1961 & 1967 & 19 & HS Grad & 29 & 39 \\
1962 & 1968 & 18 & 12 & 28 & 38 \\
1963 & 1969 & 17 & 11 & 27 & 37 \\
1964 & 1970 & 16 & 10 & 26 & 36 \\
1965 & 1971 & 15 & 9 & 25 & 35 \\
1966 & 1972 & 14 & 8 & 24 & 34 \\
1967 & 1973 & 13 & 7 & 23 & 33 \\
1968 & 1974 & 12 & 6 & 22 & 32 \\
\hline \hline
\end{tabular}

Note: Anticipated grade in 1980 is approximate, depending on state laws regarding age of school entry and a child's specific birth date. 
Table 2: Inter- and Intra-State Mobility Patterns since Birth

\begin{tabular}{|c|c|c|c|}
\hline & 1980 & 1990 & 2000 \\
\hline \multicolumn{4}{|c|}{ Census: Descriptive Statistics on Mobility } \\
\hline Percent Remained in State since Birth & 76.1 & 66.9 & 63.9 \\
\hline \multicolumn{4}{|c|}{ NLSY79: Descriptive Statistics on Mobility } \\
\hline Percent Remained in State since Birth & 77.1 & 67.5 & 65.4 \\
\hline $\begin{array}{l}\text { Percent within } 60 \text { Miles of Birth County } \\
\text { among Those in Same State Since Birth }\end{array}$ & 86.1 & 82.7 & 80.8 \\
\hline \multicolumn{4}{|c|}{ NLSY79 Regression Results: State Outmigration } \\
\hline Preschool Post $1969 *$ Coverage Rate & $\begin{array}{c}0.021 \\
(0.048)\end{array}$ & $\begin{array}{c}-0.032 \\
(0.054)\end{array}$ & $\begin{array}{c}-0.048 \\
(0.073)\end{array}$ \\
\hline Number of Observations & 9,432 & 8,215 & 6,297 \\
\hline \multicolumn{4}{|c|}{ NLSY79 Regression Results: Inter-County Moves Greater than 60 Miles } \\
\hline Preschool Post $1969 *$ Coverage Rate & $\begin{array}{c}0.011 \\
(0.033)\end{array}$ & $\begin{array}{l}-0.013 \\
(0.051)\end{array}$ & $\begin{array}{l}-0.018 \\
(0.067)\end{array}$ \\
\hline Number of Observations & 7,227 & 5,622 & 4,184 \\
\hline
\end{tabular}


Table 3: Average Characteristics of Counties, by Availability of Census Data and Estimated Strength of Signal Reception

\begin{tabular}{|c|c|c|c|c|c|}
\hline \multirow[b]{2}{*}{ Variable } & \multicolumn{3}{|c|}{1970} & \multicolumn{2}{|c|}{ Change from 1960} \\
\hline & $\begin{array}{l}\text { Not in } \\
\text { Sample }\end{array}$ & $\begin{array}{c}\text { Weak } \\
\text { Reception }\end{array}$ & $\begin{array}{c}\text { Strong } \\
\text { Reception }\end{array}$ & $\begin{array}{c}\text { Weak } \\
\text { Reception }\end{array}$ & $\begin{array}{c}\text { Strong } \\
\text { Reception }\end{array}$ \\
\hline Total Population & 27,466 & 350,343 & 386,814 & $18.4 \%$ & $16.2 \%$ \\
\hline \% Female Headed Household & 9.4 & 11.3 & 12.1 & --- & --- \\
\hline$\%$ Low Income $(<\$ 5,000)$ & 26.1 & 16.1 & 17.4 & --- & --- \\
\hline$\%$ No High School Degree & 52.5 & 44.6 & 45.0 & $-19.6 \%$ & $-20.3 \%$ \\
\hline$\%$ Black & 8.7 & 11.4 & 13.4 & $17.0 \%$ & $2.2 \%$ \\
\hline Median Family Income & $\$ 8,389$ & $\$ 10,605$ & $\$ 10,201$ & $67.4 \%$ & $66.9 \%$ \\
\hline Unemployment Rate & 4.4 & 4.5 & 4.3 & -0.8 & -0.7 \\
\hline Number of Counties & 2,674 & 191 & 153 & 187 & 151 \\
\hline
\end{tabular}


Table 4: Impact of Sesame Street on Grade-for-age Status in the 1980 Census, by Demographic Group

\begin{tabular}{|c|c|c|c|c|c|c|}
\hline & All & Boys & Girls & White, $\mathrm{NH}$ & Black, NH & Hispanic \\
\hline Mean Rate Grade-for-age & 0.797 & 0.760 & 0.834 & 0.832 & 0.703 & 0.708 \\
\hline & \multicolumn{6}{|c|}{ Aggregate Effect } \\
\hline \multirow[t]{2}{*}{$\begin{array}{c}\text { Preschool post-1969 } \\
* \text { coverage rate }\end{array}$} & $\begin{array}{c}0.105 \\
(0.025) \\
\end{array}$ & $\begin{array}{c}0.128 \\
(0.027) \\
\end{array}$ & $\begin{array}{c}0.080 \\
(0.024) \\
\end{array}$ & $\begin{array}{c}0.068 \\
(0.018) \\
\end{array}$ & $\begin{array}{c}0.105 \\
(0.031) \\
\end{array}$ & $\begin{array}{c}0.072 \\
(0.039) \\
\end{array}$ \\
\hline & \multicolumn{6}{|c|}{ Event Study Approach } \\
\hline Coverage Rate*1967-68 & $\begin{array}{l}-0.002 \\
(0.018)\end{array}$ & $\begin{array}{c}0.017 \\
(0.024)\end{array}$ & $\begin{array}{l}-0.020 \\
(0.018)\end{array}$ & $\begin{array}{c}0.011 \\
(0.016)\end{array}$ & $\begin{array}{c}0.010 \\
(0.039)\end{array}$ & $\begin{array}{l}-0.074 \\
(0.051)\end{array}$ \\
\hline Coverage Rate*1969 & $\begin{array}{c}0.075 \\
(0.027)\end{array}$ & $\begin{array}{c}0.085 \\
(0.033)\end{array}$ & $\begin{array}{c}0.064 \\
(0.027)\end{array}$ & $\begin{array}{c}0.075 \\
(0.024)\end{array}$ & $\begin{array}{c}0.100 \\
(0.048)\end{array}$ & $\begin{array}{c}0.079 \\
(0.067)\end{array}$ \\
\hline Coverage Rate*1970-72 & $\begin{array}{c}0.118 \\
(0.032)\end{array}$ & $\begin{array}{c}0.152 \\
(0.037)\end{array}$ & $\begin{array}{c}0.084 \\
(0.029)\end{array}$ & $\begin{array}{c}0.091 \\
(0.024)\end{array}$ & $\begin{array}{c}0.125 \\
(0.051)\end{array}$ & $\begin{array}{c}0.066 \\
(0.058)\end{array}$ \\
\hline Coverage Rate*1973-74 & $\begin{array}{c}0.122 \\
(0.035)\end{array}$ & $\begin{array}{c}0.157 \\
(0.041)\end{array}$ & $\begin{array}{c}0.087 \\
(0.031)\end{array}$ & $\begin{array}{c}0.083 \\
(0.026)\end{array}$ & $\begin{array}{c}0.143 \\
(0.045)\end{array}$ & $\begin{array}{c}0.044 \\
(0.054)\end{array}$ \\
\hline Sample Size & 715,458 & 359,548 & 355,910 & 512,178 & 132,828 & 61,283 \\
\hline
\end{tabular}

Notes: Each column in the top and lower blocks reflects the results from a separate regression including the listed interactions along with county fixed effects, state*birth cohort fixed effects, demographic characteristics (race/ethnicity, gender, mother's level of education, and an indicator for whether mother was present in household at time of Census), and county level policy variables (presence of Food Stamp program and expenditures on Head Start). Standard errors are estimated using a two-step bootstrap procedure where sampling is clustered at the station level in the first step and at the county level in the second step. 
Table 5: Differential Impact of Sesame Street on Grade-for-age, by County Characteristic

County Characteristic

\begin{tabular}{lcccc} 
& $\begin{array}{c}\text { Percent } \\
\text { Less than } \\
\text { HS Degree }\end{array}$ & $\begin{array}{c}\text { Percent } \\
\text { Female } \\
\text { Headed HH }\end{array}$ & $\begin{array}{c}\text { Percent } \\
\text { Families with } \\
\text { Income } \\
<\$ 5,000\end{array}$ & $\begin{array}{c}\text { Percent } \\
\text { Black }\end{array}$ \\
\hline Mean of County Characteristic & 44.6 & 11.4 & 17.0 & 11.7 \\
\hline $\begin{array}{l}\text { Preschool post-1969* coverage rate } \\
* \text { county characteristic }\end{array}$ & 0.0046 & 0.0094 & 0.0033 & 0.0037 \\
& $(0.0005)$ & $(0.0012)$ & $(0.0008)$ & $(0.0005)$ \\
Preschool post-1969* coverage rate & -0.112 & -0.046 & 0.047 & 0.011 \\
& $(0.030)$ & $(0.026)$ & $(0.024)$ & $(0.022)$ \\
\hline \hline
\end{tabular}

Notes: Each column represents a separate regression. The sample size for these regressions is 712,274. Also see notes to Table 4. 
Table 6: Aggregate Impact of Sesame Street on Educational Attainment and Labor Market Outcomes in the 1990 and 2000 Census

\begin{tabular}{|c|c|c|c|c|c|c|}
\hline & \multicolumn{3}{|c|}{1990 Census } & \multicolumn{3}{|c|}{2000 Census } \\
\hline & HS Dropout & HS Graduate & Any College & $\begin{array}{l}\text { Log Hourly } \\
\text { Wage }\end{array}$ & Employed & In Poverty \\
\hline Mean Rate & 14.4 & 32.4 & 53.2 & 2.71 & 76.8 & 10.4 \\
\hline & \multicolumn{6}{|c|}{ Aggregate Effect } \\
\hline $\begin{array}{l}\text { Preschool post-1969 } \\
* \text { coverage rate }\end{array}$ & $\begin{array}{c}0.005 \\
(0.008)\end{array}$ & $\begin{array}{c}0.018 \\
(0.012)\end{array}$ & $\begin{array}{l}-0.023 \\
(0.012)\end{array}$ & $\begin{array}{c}0.026 \\
(0.015)\end{array}$ & $\begin{array}{c}0.027 \\
(0.009)\end{array}$ & $\begin{array}{l}-0.013 \\
(0.006)\end{array}$ \\
\hline & \multicolumn{6}{|c|}{ Event Study Approach } \\
\hline Coverage Rate*1967-68 & $\begin{array}{l}-0.008 \\
(0.010)\end{array}$ & $\begin{array}{l}-0.008 \\
(0.013)\end{array}$ & $\begin{array}{c}0.017 \\
(0.011)\end{array}$ & $\begin{array}{c}0.021 \\
(0.019)\end{array}$ & $\begin{array}{c}0.000 \\
(0.011)\end{array}$ & $\begin{array}{l}-0.001 \\
(0.010)\end{array}$ \\
\hline Coverage Rate*1969 & $\begin{array}{l}-0.016 \\
(0.013)\end{array}$ & $\begin{array}{l}-0.007 \\
(0.014)\end{array}$ & $\begin{array}{c}0.023 \\
(0.016)\end{array}$ & $\begin{array}{c}0.025 \\
(0.024)\end{array}$ & $\begin{array}{c}0.006 \\
(0.015)\end{array}$ & $\begin{array}{l}-0.001 \\
(0.011)\end{array}$ \\
\hline Coverage Rate*1970-72 & $\begin{array}{l}-0.010 \\
(0.010)\end{array}$ & $\begin{array}{l}-0.002 \\
(0.012)\end{array}$ & $\begin{array}{c}0.012 \\
(0.012)\end{array}$ & $\begin{array}{c}0.045 \\
(0.020)\end{array}$ & $\begin{array}{c}0.020 \\
(0.011)\end{array}$ & $\begin{array}{l}-0.013 \\
(0.009)\end{array}$ \\
\hline Coverage Rate*1973-74 & $\begin{array}{c}0.012 \\
(0.012)\end{array}$ & $\begin{array}{c}0.038 \\
(0.018)\end{array}$ & $\begin{array}{l}-0.050 \\
(0.020)\end{array}$ & $\begin{array}{c}0.031 \\
(0.020)\end{array}$ & $\begin{array}{c}0.040 \\
(0.014)\end{array}$ & $\begin{array}{l}-0.016 \\
(0.010)\end{array}$ \\
\hline
\end{tabular}

\footnotetext{
Notes: The sample sizes for the 1990 and 2000 Census models are 667,530 and 458,043, respectively. Also see notes to Table 4
} 
Table 7. Impact of Sesame Street on Cognitive and Non-cognitive Outcomes:

High School and Beyond Data

Academic Achievement

\begin{tabular}{lcccc} 
& \multicolumn{3}{c}{ Standardized Test Score } & Mostly A's and \\
\cline { 2 - 4 } & Math & Vocabulary & Reading & B's in HS \\
\hline Coverage rate* & 0.077 & 0.014 & 0.082 & -0.019 \\
Soph in 1980 & $(0.055)$ & $(0.058)$ & $(0.059)$ & $(0.026)$ \\
Sophomore in 1980 & 0.355 & 0.299 & 0.319 & 0.103 \\
& $(0.233)$ & $(0.209)$ & $(0.246)$ & $(0.165)$ \\
Group Mean & & & & \\
Observations & 0.045 & 0.045 & 0.041 & 0.524 \\
\hline
\end{tabular}

\section{Socio-Developmental Outcomes}

\begin{tabular}{lccccc} 
& $\begin{array}{c}\text { Locus of } \\
\text { Control }\end{array}$ & $\begin{array}{c}\text { Self } \\
\text { Esteem }\end{array}$ & $\begin{array}{c}\text { No Discipline } \\
\text { Problem }\end{array}$ & $\begin{array}{c}\text { Doesn’t Cut } \\
\text { Class }\end{array}$ & $\begin{array}{c}\text { Likes Working } \\
\text { Hard at School }\end{array}$ \\
\hline Coverage rate* & & & & & \\
$\quad$ Soph in 1980 & 0.020 & 0.096 & -0.010 & -0.045 & -0.047 \\
& $(0.059)$ & $(0.062)$ & $(0.020)$ & $(0.030)$ & $(0.032)$ \\
Sophomore in 1980 & 0.064 & 0.240 & 0.021 & 0.059 & -0.161 \\
& $(0.340)$ & $(0.333)$ & $(0.083)$ & $(0.140)$ & $(0.162)$ \\
& & & & & \\
Group Mean & 0.025 & 0.003 & 0.865 & 0.57 & 0.554 \\
Observations & 49,198 & 49,264 & 50,856 & 50,835 & 48,461 \\
\hline \hline
\end{tabular}

Notes: Each column within the top and bottom panels is a separate regression. Test scores, locus of control and self-esteem, are demeaned and standardized within each cohort. Controls include gender, race, parental education, urbanicity, 1980 family income, single parent households, county level Food Stamp availability, county level Head Start per capita expenditure, and school fixed effects (which eliminate the main effect of the coverage rate). Sample composed of all 1980 sophomores who were enrolled in $12^{\text {th }}$ grade in the 1982 survey and all 1980 seniors. Standard errors are estimated using a bootstrap procedure where sampling is clustered at the school level. 
Figure 1: Availability of Sesame Street on VHF/UHF Channels, by Television Market

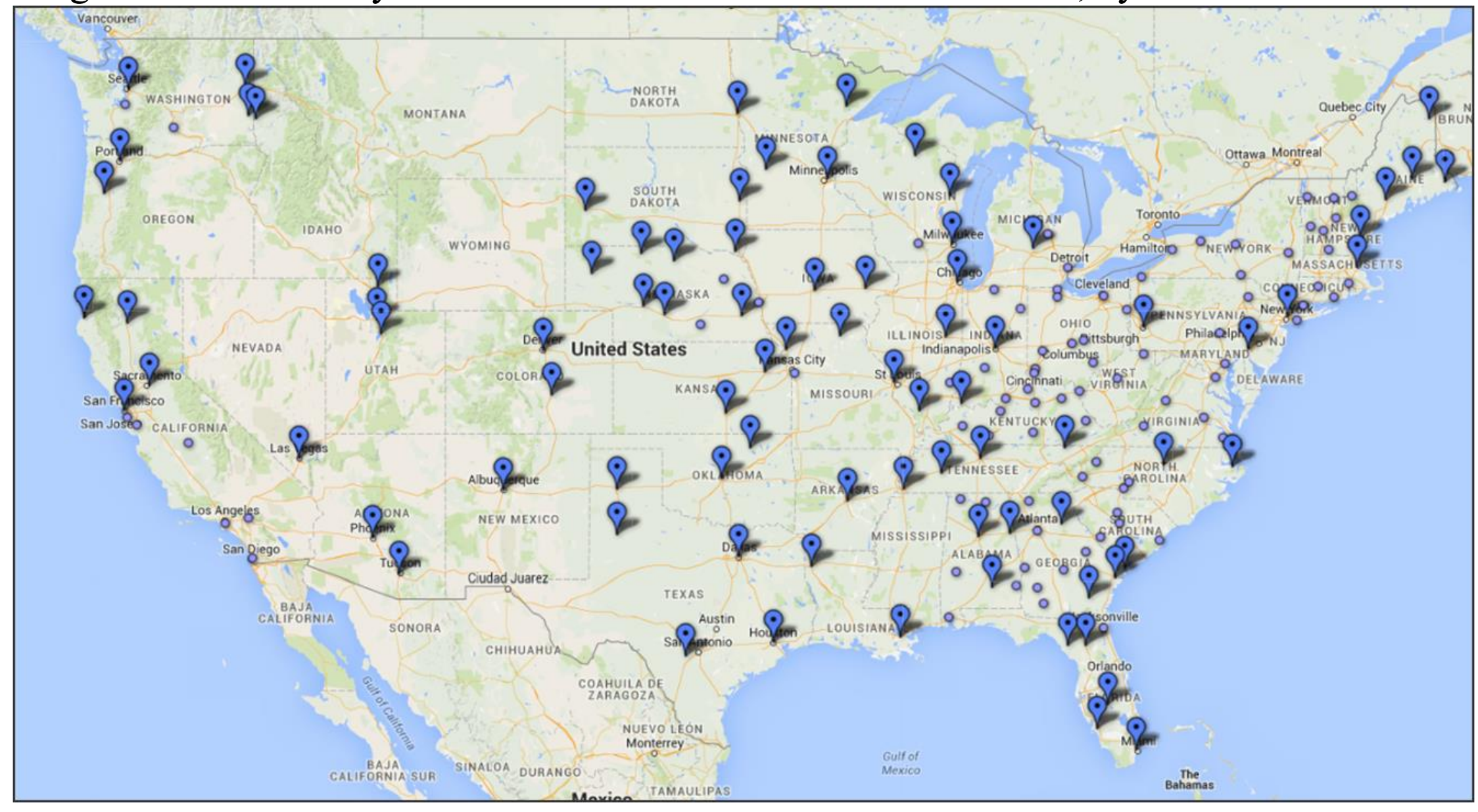

$\uparrow$ VHF Channel

- UHF Channel 
Figure 2: Sesame Street Simulated Coverage Rates by County, 1969

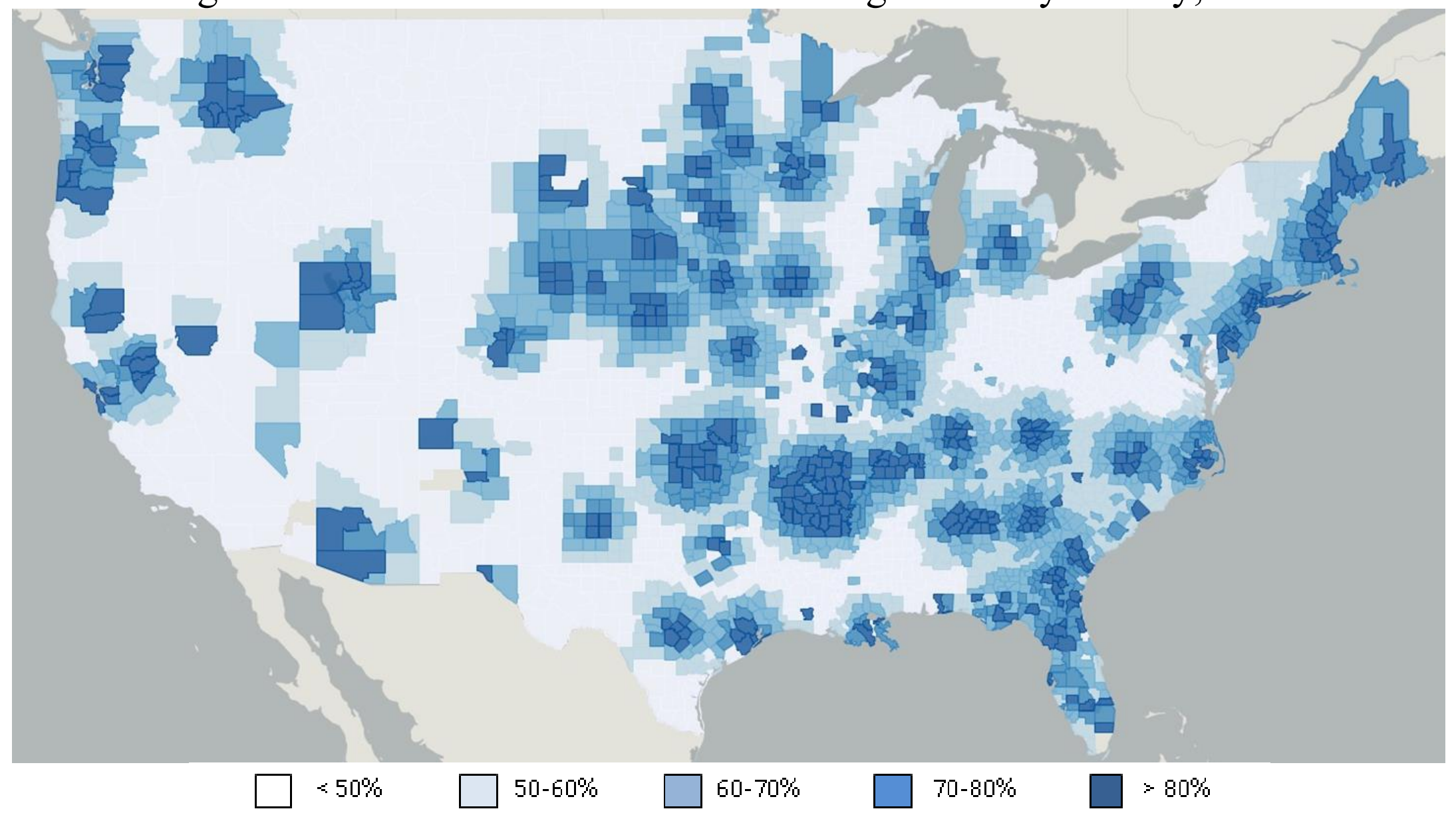


Figure 3: Relationship between Sesame Street Simulated Coverage Rates and Nielsen Ratings in Selected TV Markets

80

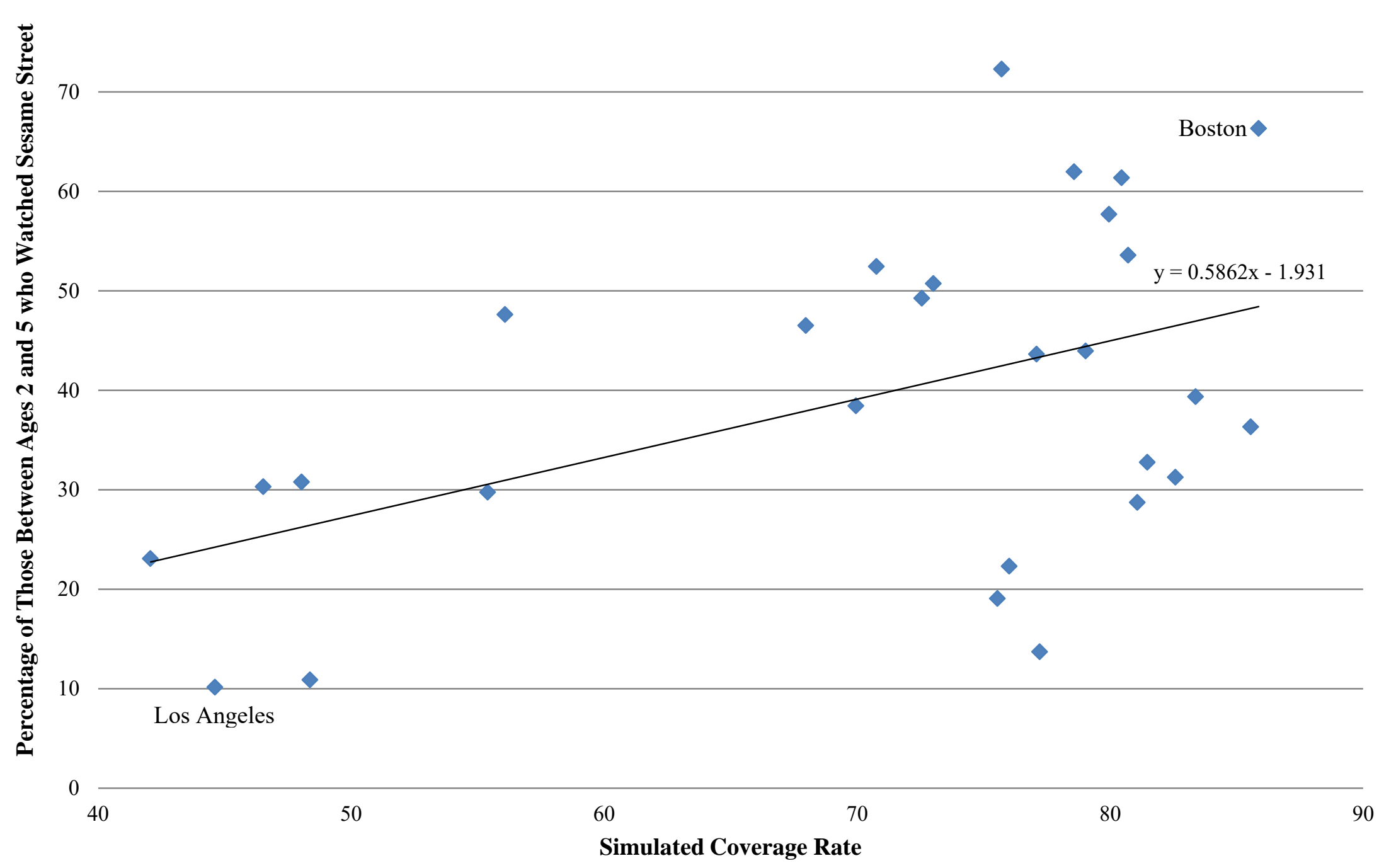


Figure 4: Counties Separately Identified in the 1980 Census

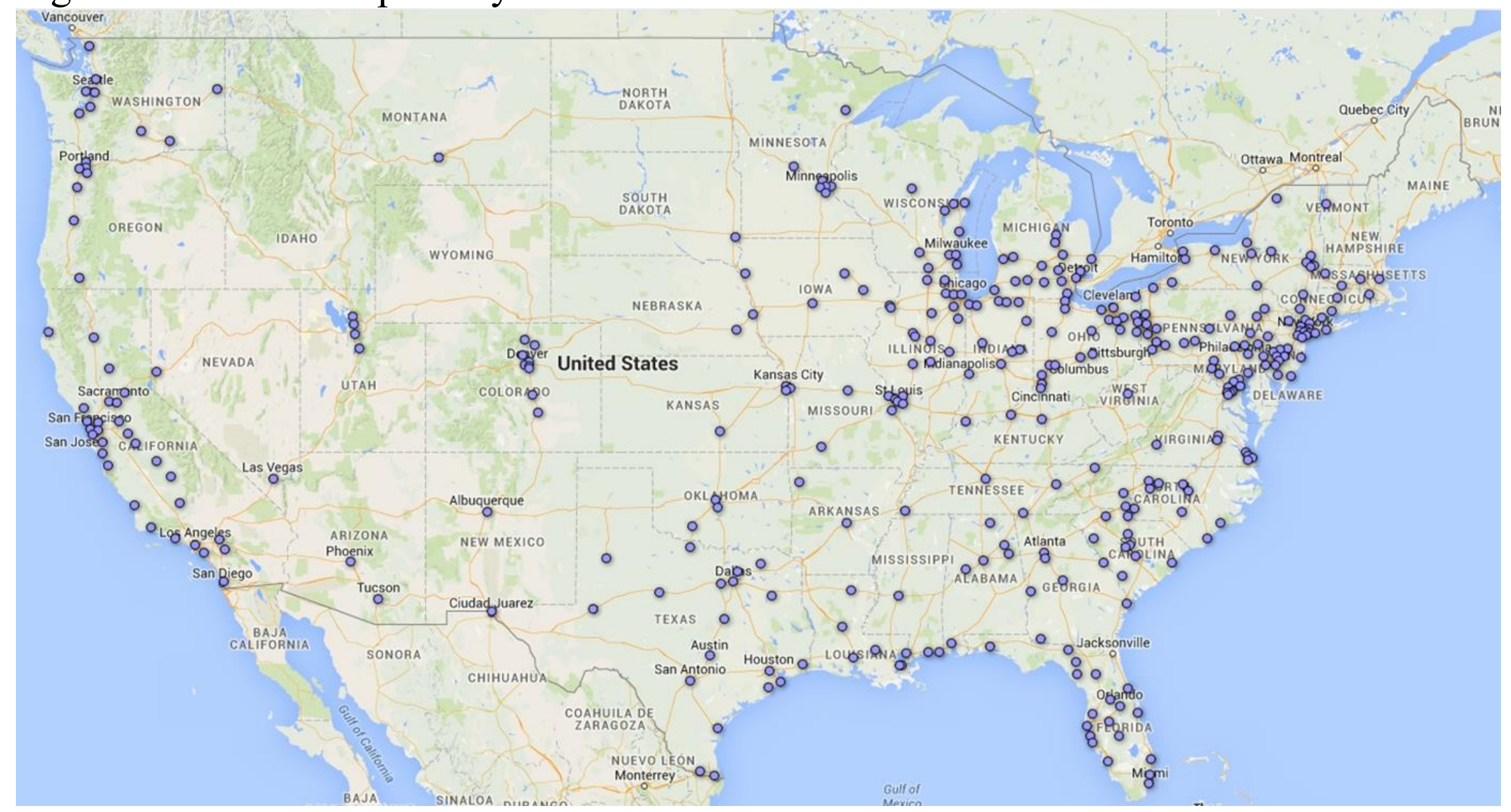


Figure 5: Impact of the Introduction of Sesame Street

on Grade-for-Age Status in 1980

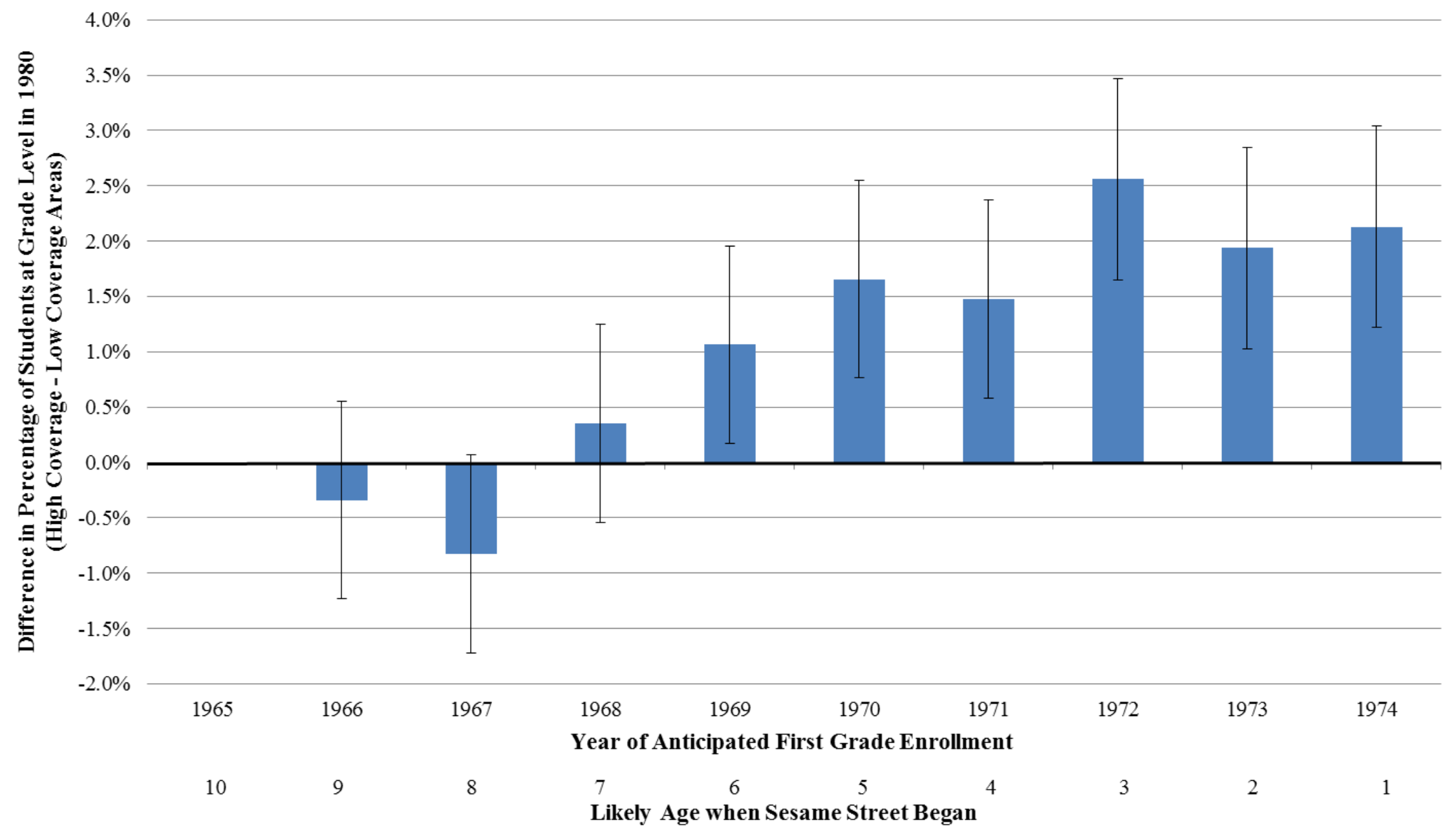

note: High coverage areas are defined to be those with above average simulated coverage rates. Differences are normalized to equal zero when the year of anticipated first grade enrollment is 1968 .

source: Authors' calculations based on analysis of 1980 Census Data. 
Figure 6: Impact of the Introduction of Sesame Street on Grade-for-Age Status in 1980, by Level of Economic Disadvantage in County

$6.0 \%$

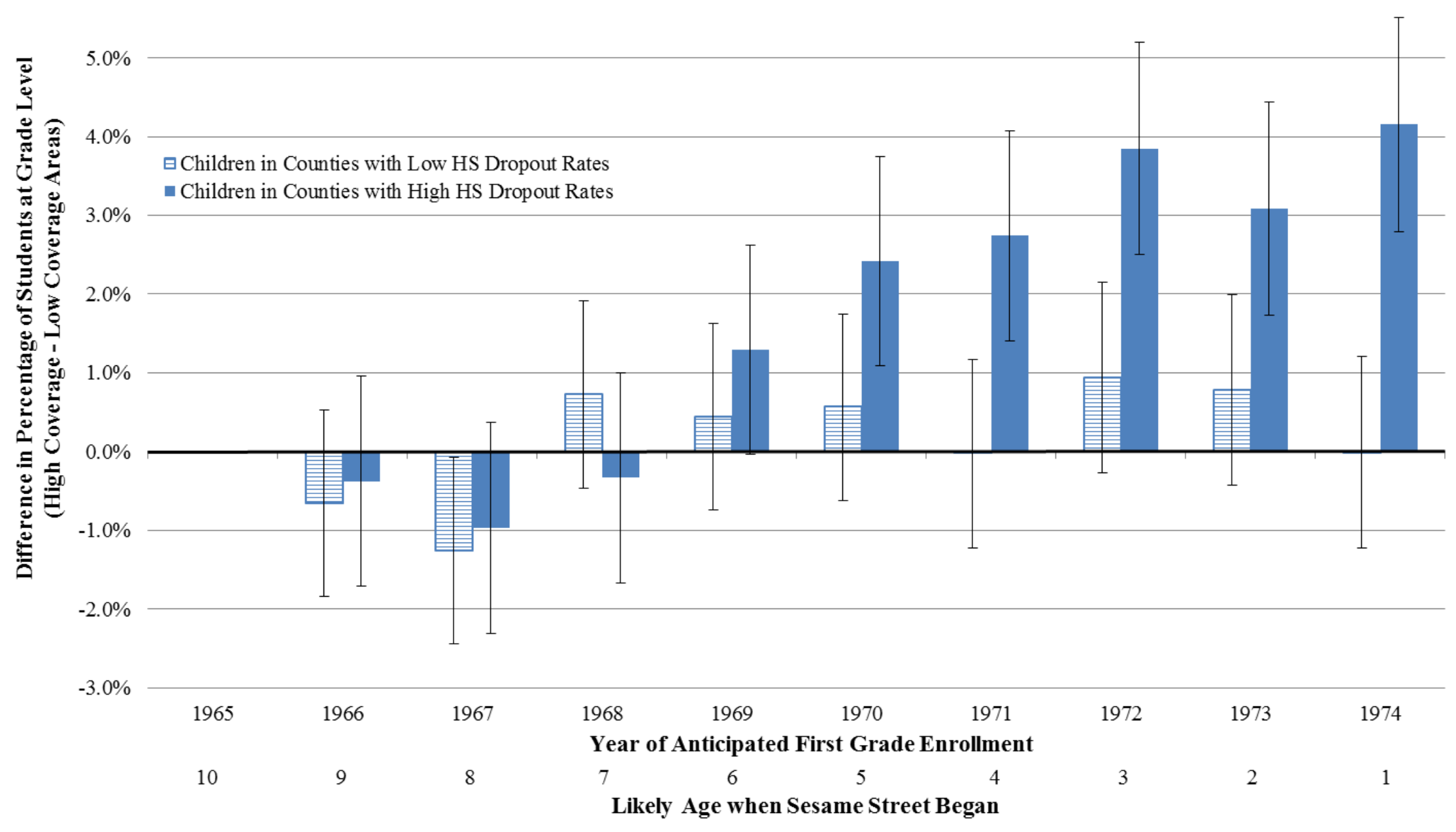

note: See notes to Figure 5.

source: Authors' calculations based on analysis of 1980 Census Data. 
Figure 7: Impact of the Introduction of Sesame Street on the Likelihood of Being a High School Graduate in 1990

$2.0 \%$
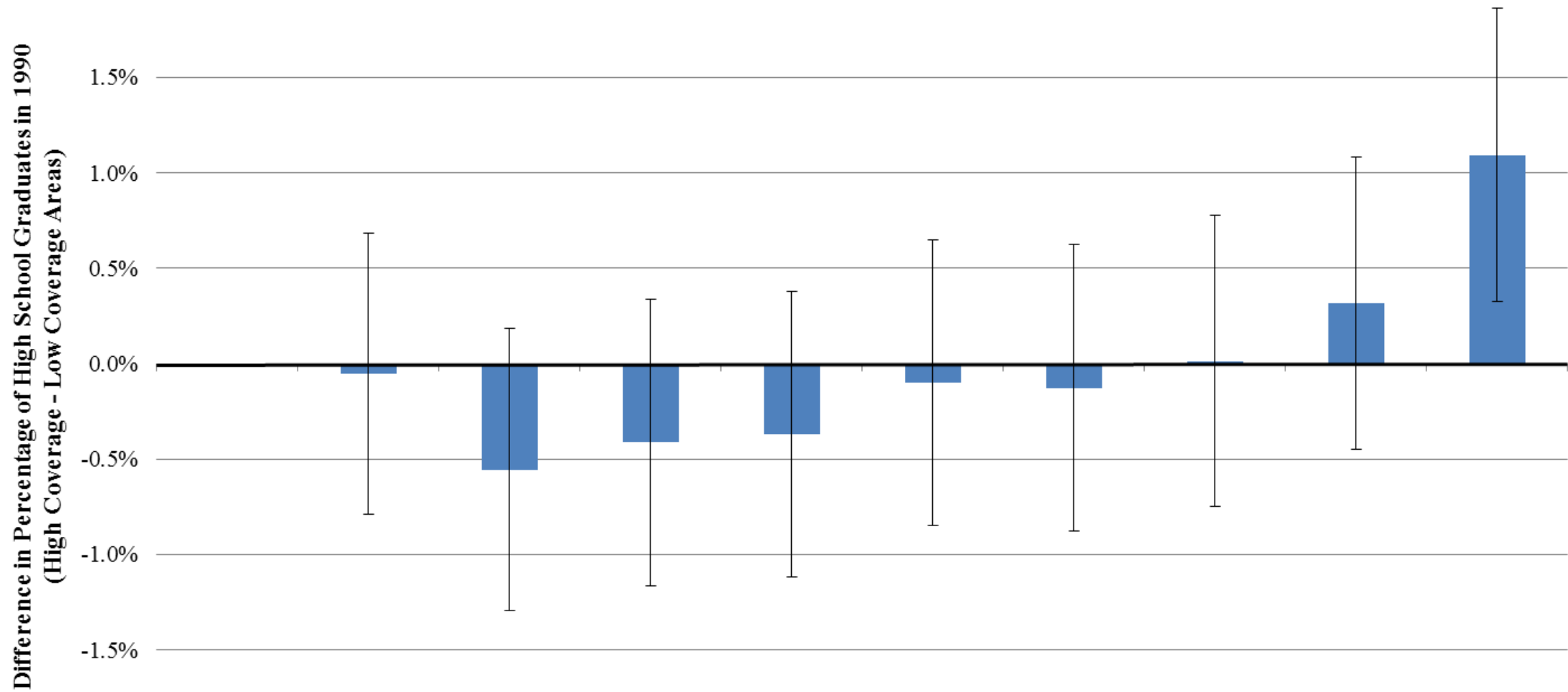

$-1.5 \%$

$-2.0 \%$

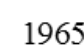

1966

1967

1968

1969

1970

1971

1972

1973

1974

10

9

8

Year Age 6

Likely Age when Sesame Street Began

4

2

note: See notes to Figure 5.

source: Authors' calculations based on analysis of 1990 Census Data. 
Figure 8: Impact of the Introduction of Sesame Street

on the Employment Rate in $\mathbf{2 0 0 0}$

$2.0 \%$

$1.5 \%$

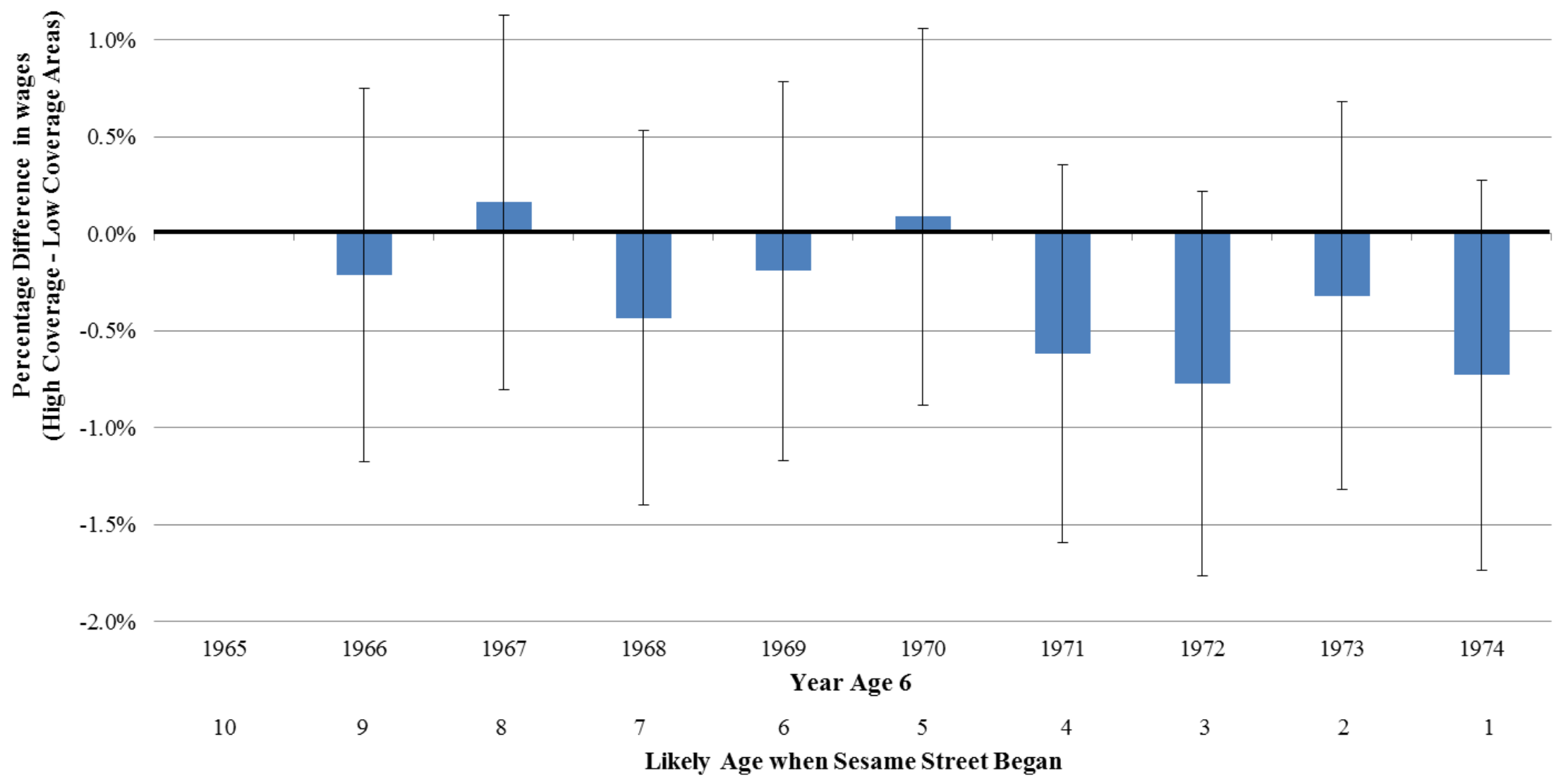

note: See notes to Figure 5.

source: Authors' calculations based on analysis of 2000 Census Data. 


\section{Data Appendix 1: Estimating Sesame Street Coverage Rates}

An important determinant of the potential influence of Sesame Street upon its introduction was the ability of households to receive its broadcast. Indications at that time suggest that only around two-thirds of households could do so (Davis, 2008). For the purposes of this research project, identifying which areas of the country had greater access than others is a critical issue.

Obtaining that information, however, is a difficult task. Since its inception, Sesame Street has been commonly broadcast on non-commercial television stations that were members of the Public Broadcasting Service (PBS). A major reason for television networks to study the number of households in an area watching their shows is to set the price of advertising time. Noncommercial networks, by definition, do not sell advertising time, providing them with less of an incentive to pay the expense of regularly obtaining location-specific reception capabilities and audience size.

These data are available, however, for commercial networks and we take advantage of them to simulate county-level estimates of Sesame Street coverage rates. During the early years of the television industry, the periodic publication, TV Factbook, provided categorical data on "net weekly circulation" by county for every commercial television station in the country. This statistic measures the percentage of television households in that county that viewed any show broadcast by a nearby station at least once over the course of a week. By 1969, 95 percent of all households owned at least one television set (U.S. Bureau of the Census, 1970), so television households closely approximate all households. With limited station options (three major networks and very limited cable television), viewing any show broadcast by a particular station at least once in a week is a strong indicator of the ability of the household to receive that 
station's signal. We interpret this statistic as the station's "coverage rate," in a county. Counties are identified as those in which the coverage rate from a nearby station is 5 to 24 percent, 25 to 50 percent, or greater than 50 percent. We take advantage of the data from this source from 1968 , before Sesame Street was introduced (Television Digest, Inc., 1968).

The TV Factbook also provides additional detail that is critical for our analysis, namely the technical specifications of every television station in the country. These specifications include the exact location (latitude and longitude in seconds) of every broadcast tower, the height of the tower above the ground, the channel number of the station, and the power of the broadcast signal. Importantly, these data are available for every station, commercial and non-commercial, including those that were members of the National Educational Television (NET) network in 1968, which would become PBS when it was formed in 1969.

The approach that we use to simulate Sesame Street coverage rates by county is to determine the empirical relationship between commercial stations' broadcast tower and the county level coverage rates using each station's technical specifications. We then apply that relationship to the technical specifications of all stations, including those that were noncommercial, to simulate county level coverage rates. That statistic will be the key explanatory variable in our analysis.

An important component of this empirical coverage relationship is the distance between the television tower and the nearby counties. The TV Factbook provides us with information on the latitude and longitude of the tower. To determine how far away nearby counties are, we use data on the latitude and longitude of the population centroids of those counties in 1970 (U.S. Bureau of the Census, 1974). We can construct the distance between the tower and the county using these latitude and longitude statistics. We define "nearby" counties to be those that are 
within 200 miles of the television tower. Inspection of the data suggests that television reception outside of that range is sufficiently uncommon that we can ignore it. Although distance is a fundamental component of broadcast signal reception, the other technical specifications available for each station should matter as well. The higher the television tower is, the further away the signal should be received. Signal strength should play a similar role.

Another factor that is important is the frequency of the broadcast, particularly whether it is very high frequency (VHF) or ultra-high frequency (UHF). VHF stations can be identified as those with channel numbers of 2 through 13 and UHF stations are those with channel numbers above 13. It is well-known that reception of UHF stations at the time was considerably inferior to that of VHF stations. This was partly attributable to technological limitations of UHF transmission and partly because UHF receivers in television sets were inferior or even nonexistent (McDowell, 2006). In fact, as of January 1969, only 55 percent of households owned a television that could receive UHF channels (U.S. Bureau of the Census, 1970). This means that whether the station broadcast in VHF or UHF played a large role in determining its coverage rate in the area. Many PBS stations broadcast in UHF (including Washington, DC and Los Angeles), contributing to their coverage limitations.

In determining the relationship between coverage, distance, and technical specifications, a unit of observation is a county/commercial station pair. We restrict our analysis to those pairs where we have complete data, including coverage rates in nearby counties and the coordinates of the population centroid in the covered county because of the importance of distance in this analysis. Using these data, we further restrict the sample to county/station pairs within a 200 mile distance. Finally, we restrict the sample to exclude those stations that are satellites of another because it complicates the computation of distance from the receiving county and the 
transmission tower. In the end, the sample of county/station pairs used in estimation totals $14,397$.

In our empirical model, the dependent variable is the coverage rate and the explanatory variables reflect the technical specifications of the commercial stations. Recall that the available coverage rates are categorical (5-24 percent, 25-50 percent, and over 50 percent). To linearize the relationship, we assume an average coverage rate within categories of 20,40, and 90 percent.

The results of our empirical exercise are reported in Appendix Table A1. The results are consistent with what we would have predicted, particularly regarding the role of distance and UHF reception. A county that is 100 miles away from the tower has about a 50 percentage point lower likelihood of receiving the signal. Stations that broadcast over a UHF channel experience coverage rates that are 42 percentage points lower than a VHF channel even in the immediate vicinity of the broadcast tower. That deficit increases 10 percentage points for a UHF channel if the county is 100 miles away from the broadcast tower. In essence, it is very unlikely for UHF signals to be received beyond 100 miles from the tower.

We then apply these parameters to the technical specifications of the non-commercial stations to simulate coverage rates by county for their broadcast signals. We have two indicators that these estimates provide a good approximation of coverage rates for PBS and Sesame Street, as we have described earlier in this appendix and in the text of the paper. First, the national coverage rate from these county level estimates is very similar to previously reported coverage rates for Sesame Street. Second, when we aggregate these data by metropolitan area and compare estimated coverage rates to Nielsen ratings in those areas, they correlate strongly. 
Appendix Table A1: Relationship between Station Technical Specifications and Coverage in Nearby County

\begin{tabular}{lcc}
\hline & & \\
Variable & Coefficient & Standard Error \\
\hline Distance & -5.133 & 0.237 \\
UHF & -42.311 & 5.555 \\
Distance*UHF & 3.126 & 0.797 \\
Height Above Ground & 0.161 & 0.153 \\
Visual Power (Kw) & -1.102 & 0.466 \\
Intercept & 94.048 & 1.973 \\
\hline Notes: Distance is measured in 10 mile increments. Height above ground is measured \\
in increments of 100 feet. Visual power is measured in increments of 100 kilowatts. \\
Standard errors are clustered at the station level.
\end{tabular}




\section{Data Appendix 2: \\ Identifying States and Counties in High School and Beyond Data}

No public or restricted release version of the High School and Beyond (HSB) survey contains state or county identifiers. A contextual data file, however, was released at one point (currently available through ICPSR), which included supplemental local labor market indicators, containing data from the Bureau of Labor Statistics (BLS) and the Bureau of Economic Analysis (BEA). We used these data and "reverse engineered" them to generate state and county level identifiers. This appendix details our approach.

The BLS component in the local labor market supplement contains 21 measures of employment growth, unemployment and wages including the state, county and Standard Metropolitan Statistical Area (SMSA) annual unemployment rates for 1980, 1981, and 1982 as well as employment growth rates that were constructed from the civilian labor force and employment variables. In addition, the annual hourly average wage for manufacturing is provided at the state and SMSA level for these same years. Variables that were reported in levels, such as the number participating in the labor force, number employed, and number unemployed were dropped in order to maintain anonymity.

The BEA component of the local labor market supplement contains 30 measures of annual per capita personal income, total personal income annual growth, employment to population growth ratios, and within sample population quartile indicators for the years 1980 and 1981. Once again, variables reported in levels, such as total personal income and population were dropped for confidentiality. Although unique identifiers (such as population or number of unemployed workers) were not provided, the combination of these local labor market variables can be used to accurately identify the states and counties of all of the HSB survey schools. 
With these data, we found that the combination of state unemployment rates for 1980 , 1981, and 1982 uniquely identifies each state and the District of Columbia. We then kept only the state observations and merged the BLS state level unemployment data onto the HSB school level state unemployment rates for the corresponding years using the 1980-1982 unemployment rates as identifiers. All 1,015 schools merged, thus identifying the state each school is located in.

After linking each school to a state, we found that the combination of state and the BEA county level per capita personal income for the years 1980 and 1981 uniquely identify every county in the United States. In other words, at the state level, county per capita personal income from 1980 and 1981 uniquely identifies all U.S. counties. We then merged the BEA personal income data onto the HSB data using state, and 1980-1981 per capita personal income as unique identifiers. Once again, all 1,015 schools were successfully linked to a county in their previously determined state. In short, we use a two-step process of first identifying the state of each school by BLS state level unemployment data, then identifying the county of each school by BEA county level per capita personal income and the state. This method links every school in the HSB survey to its corresponding state and county, allowing us to use the county level television reception data for identification.

In order to check the validity of our match, we considered the match quality of 1980 and 1981 county level total personal income annual growth (CTPIAG) and per capita personal income as a percent of the national average, as well as state level total personal income growth, per capita personal income as a percent of the national average, and state level per capita personal income, which we had obtained and were included in the HSB data. Using the matching method described above, we found that all but 1981 CTPIAG exactly matched the HSB data. The 1981 CTPIAG matched on all but 7 state-county observations. Upon additional 
inspection, we found that in each of these cases our value was exactly 1 unit higher, the result of a rounding difference between the two datasets. $99.31 \%$ of the data matched exactly, and $100 \%$ matched after correcting for this difference in rounding. As an additional validity check, we use the HSB provided Census Region for each school, and found that all of our reverse engineered states fall within the correct Census Region. 
Appendix Table 1: First Stage Regressions of Sesame Street Coverage Rates (1980 Census)

\begin{tabular}{|c|c|c|c|c|c|c|}
\hline & All & Boys & Girls & White, NH & Black, NH & Hispanic \\
\hline $\begin{array}{l}\text { Preschool post-1969 } \\
\text { *Distance to Closest Tower } \\
\text { Broadcasting Sesame Street }\end{array}$ & $\begin{array}{c}-0.041 \\
(0.002)\end{array}$ & $\begin{array}{l}-0.041 \\
(0.002)\end{array}$ & $\begin{array}{c}-0.041 \\
(0.002)\end{array}$ & $\begin{array}{l}-0.040 \\
(0.002)\end{array}$ & $\begin{array}{c}-0.042 \\
(0.002)\end{array}$ & $\begin{array}{c}-0.044 \\
(0.002)\end{array}$ \\
\hline $\begin{array}{l}\text { Preschool post-1969 } \\
\text { * Closest Tower Broadcasts } \\
\text { Over UHF }\end{array}$ & $\begin{array}{c}-0.245 \\
(0.018)\end{array}$ & $\begin{array}{c}-0.245 \\
(0.018)\end{array}$ & $\begin{array}{c}-0.245 \\
(0.018)\end{array}$ & $\begin{array}{l}-0.246 \\
(0.015)\end{array}$ & $\begin{array}{c}-0.229 \\
(0.031)\end{array}$ & $\begin{array}{c}-0.196 \\
(0.038)\end{array}$ \\
\hline F-Statistic on Omitted Instruments & 426.45 & 424.14 & 427.57 & 453.04 & 426.57 & 79.47 \\
\hline
\end{tabular}

Notes: Each column reflects the results from a separate regression where the dependent variable is the interaction between preschool post 1969 and estimated coverage rate in the county of residence. Explanatory variables include those listed instruments along with county fixed effects, state*birth cohort fixed effects, demographic characteristics (race/ethnicity, gender, mother's level of education, and an indicator for whether mother was present in household at time of Census), and county-level presence of Food Stamp program and county-level expenditures on Head Start. 
Appendix Table 2: IV Estimates of the Impact of Sesame Street on Grade-for-age Status in the 1980 Census, by Demographic Group

\begin{tabular}{|c|c|c|c|c|c|c|}
\hline & All & Boys & Girls & White, $\mathrm{NH}$ & Black, NH & Hispanic \\
\hline Mean Rate Grade-for-age & 0.797 & 0.760 & 0.834 & 0.832 & 0.703 & 0.708 \\
\hline & \multicolumn{6}{|c|}{ Aggregate Effect } \\
\hline $\begin{array}{c}\text { Preschool post-1969 } \\
* \text { coverage rate }\end{array}$ & $\begin{array}{c}0.097 \\
(0.028)\end{array}$ & $\begin{array}{c}0.125 \\
(0.030)\end{array}$ & $\begin{array}{c}0.069 \\
(0.028)\end{array}$ & $\begin{array}{c}0.046 \\
(0.022)\end{array}$ & $\begin{array}{c}0.136 \\
(0.041)\end{array}$ & $\begin{array}{c}0.059 \\
(0.044)\end{array}$ \\
\hline & \multicolumn{6}{|c|}{ Event Study Approach } \\
\hline Coverage Rate*1967-68 & $\begin{array}{l}-0.010 \\
(0.020)\end{array}$ & $\begin{array}{c}0.015 \\
(0.028)\end{array}$ & $\begin{array}{c}-0.032 \\
(0.021)\end{array}$ & $\begin{array}{c}0.007 \\
(0.018)\end{array}$ & $\begin{array}{c}-0.019 \\
(0.051)\end{array}$ & $\begin{array}{c}-0.082 \\
(0.064)\end{array}$ \\
\hline Coverage Rate*1969 & $\begin{array}{c}0.078 \\
(0.028)\end{array}$ & $\begin{array}{c}0.100 \\
(0.038)\end{array}$ & $\begin{array}{c}0.053 \\
(0.027)\end{array}$ & $\begin{array}{c}0.073 \\
(0.028)\end{array}$ & $\begin{array}{c}0.074 \\
(0.056)\end{array}$ & $\begin{array}{c}0.121 \\
(0.069)\end{array}$ \\
\hline Coverage Rate*1970-72 & $\begin{array}{c}0.110 \\
(0.034)\end{array}$ & $\begin{array}{c}0.156 \\
(0.040)\end{array}$ & $\begin{array}{c}0.064 \\
(0.030)\end{array}$ & $\begin{array}{c}0.071 \\
(0.028)\end{array}$ & $\begin{array}{c}0.132 \\
(0.061)\end{array}$ & $\begin{array}{c}0.065 \\
(0.063)\end{array}$ \\
\hline Coverage Rate*1973-74 & $\begin{array}{c}0.108 \\
(0.039)\end{array}$ & $\begin{array}{c}0.148 \\
(0.045)\end{array}$ & $\begin{array}{c}0.069 \\
(0.035)\end{array}$ & $\begin{array}{c}0.053 \\
(0.030)\end{array}$ & $\begin{array}{c}0.164 \\
(0.057)\end{array}$ & $\begin{array}{c}0.021 \\
(0.065)\end{array}$ \\
\hline Sample Size & 715,458 & 359,548 & 355,910 & 512,178 & 132,828 & 61,283 \\
\hline
\end{tabular}

Notes: Each column in the top and lower blocks reflects the results from a separate regression including the listed interactions along with county fixed effects, state*birth cohort fixed effects, demographic characteristics (race/ethnicity, gender, mother's level of education, and an indicator for whether mother was present in household at time of Census), and county level policy variables (presence of Food Stamp program and expenditures on Head Start). Standard errors are clustered at the county level. 
Appendix Table 3: IV Estimates of the Differential Impact of Sesame Street on Grade-for-age, by County Characteristic

County Characteristic

\begin{tabular}{|c|c|c|c|c|}
\hline & $\begin{array}{c}\text { Percent } \\
\text { Less than } \\
\text { HS Degree }\end{array}$ & $\begin{array}{c}\text { Percent } \\
\text { Female } \\
\text { Headed HH }\end{array}$ & $\begin{array}{c}\text { Percent } \\
\text { Families with } \\
\text { Income } \\
<\$ 5,000\end{array}$ & $\begin{array}{l}\text { Percent } \\
\text { Black }\end{array}$ \\
\hline Mean of County Characteristic & 44.6 & 11.4 & 17.0 & 11.7 \\
\hline $\begin{array}{l}\text { Preschool post- } 1969 * \text { coverage rate } \\
\quad * \text { county characteristic }\end{array}$ & $\begin{array}{c}0.0056 \\
(0.0007)\end{array}$ & $\begin{array}{c}0.0137 \\
(0.0019)\end{array}$ & $\begin{array}{c}0.0057 \\
(0.0011)\end{array}$ & $\begin{array}{c}0.0058 \\
(0.0009)\end{array}$ \\
\hline Preschool post- $1969 *$ coverage rate & $\begin{array}{l}-0.165 \\
(0.044)\end{array}$ & $\begin{array}{l}-0.149 \\
(0.038)\end{array}$ & $\begin{array}{l}-0.011 \\
(0.030)\end{array}$ & $\begin{array}{l}-0.069 \\
(0.036)\end{array}$ \\
\hline
\end{tabular}

Notes: Each column represents a separate regression. The sample size for these regressions is 712,274. Also see notes to Table 4. 
